\title{
Theoretical Calculation of Absolute Radii of Atoms and Ions. Part 1. The Atomic Radii
}

\section{*Dulal C. Ghosh and Raka Biswas}

Department of Chemistry, University of Kalyani, Kalyani-741-235, India.

E-mail: dulal@klyuniv.ernet.in

Received: 22 December 2001 / Accepted: 10 January 2002 / Published: 28 February 2002

\begin{abstract}
A set of theoretical atomic radii corresponding to the principal maximum in the radial distribution function, $4 \pi r^{2}{ }^{2}$ for the outermost orbital has been calculated for the ground state of 103 elements of the periodic table using Slater orbitals. The set of theoretical radii are found to reproduce the periodic law and the Lother Meyer's atomic volume curve and reproduce the expected vertical and horizontal trend of variation in atomic size in the periodic table. The d-block and f-block contractions are distinct in the calculated sizes. The computed sizes qualitatively correlate with the absolute size dependent properties like ionization potentials and electronegativity of elements. The radii are used to calculate a number of size dependent periodic physical properties of isolated atoms viz., the diamagnetic part of the atomic susceptibility, atomic polarizability and the chemical hardness. The calculated global hardness and atomic polarizability of a number of atoms are found to be close to the available experimental values and the profiles of the physical properties computed in terms of the theoretical atomic radii exhibit their inherent periodicity. A simple method of computing the absolute size of atoms has been explored and a large body of known material has been brought together to reveal how many different properties correlate with atomic size.
\end{abstract}

\section{Introduction}

The concept of atomic and ionic radii has been found to be very useful in understanding, explaining, correlating and even predicting many physico-chemical properties of atoms, ions and molecules. The periodicity of chemical and physical properties of the elements has been recognized 
from the date of early history of chemistry. The atomic volume curve of Lother Meyer was a striking example of periodicity of physical properties of elements. The atomic size has been also an important periodic property of the elements. The atomic and ionic radii values are important input in many calculations of size dependent physico-chemical properties of isolated atoms. The crystal chemists have tried for many years to treat atoms and ions as hard spheres and published series of atomic and ionic radii with the only significance that such atomic and ionic radii, when added, reproduce the minimum distance of separation between atoms and ions respectively in crystal lattices. Approximate additivity of atomic and ionic radii were noted by early investigators like Goldschmidt et al [1], Pauling [2], Zachariasen [3], and Bragg [4]. However, the inter atomic or inter ionic distance depend upon the crystal type, its allotropic modification, co-ordination number, temperature etc. Unfortunately this very important property - the size concept of atoms and ions is heavily underplayed. The text books dealing with this size aspects of atoms or ions never make the position distinctly clear as to the meaning and purport of the terms 'atomic' or 'ionic' radii and the term 'radii' is kept vague. But invariably the text books display one or the other chart of atomic and ionic radii and recently there has been a proliferation of the tables and data of atomic and ionic radii with bewildering array of terms including bonded, non-bonded, ionic, covalent and van der Waals radii [5]. But such radii data though useful in reproducing the inter atomic/ionic distances for the particular purposes but not useful in computing the radial dependent absolute properties of atoms. Also, there is no means of verifying the merit of a set of radii determined experimentally or calculated theoretically because, there is no experimental value of the sizes of atoms and ions [6].

According to quantum mechanical view, the atoms and the ions do not have any rigid shape or size and hence the question of atomic and ionic radii simply does not arise in the true sense of the term. However, chemical experience suggests that the atoms and ions do have an effective size because, the atoms and ions cannot approach each other beyond certain limiting distance under the influence of forces encountered in chemical interactions. The determination of the empirical atomic and ionic radii, on the basis of hard sphere approximation model, has a history stretching back to the work of Bragg ${ }^{4}$ in 1920's to the work of Slater [7] in the year 1964. Attempts of computing theoretical atomic and ionic radii within the scope of Self Consistent Field (SCF) theory are also reported $[7,8]$.

The inherent approximation of the SCF method suggests that each electron have its own oneelectron function or orbital in many-electron situation. The fact that each electron in a many electron system should have one-electron function is a pre-quantum mechanical thinking [9] when it was pointed out that many spectroscopic facts could be rationalized if energy levels were identified with those of a single electron moving in a central field. Slater [7] argued that there must be a connection between empirically determined atomic and ionic size with the wave functions of atoms and ions and pointed out a good correlation between the atomic radii and the distance of maximum charge density in the outermost electron shell of the atom. To be more precise, according to the suggestion of Slater, the principal maxima of the radial charge density distribution function of the outermost orbital of the atom 
may be considered as its theoretical atomic radius. Slater [7] published a set of atomic radii computed through comparison of a large number of crystal data and it is claimed that such crystal radii are very close to the theoretical atomic radii calculated by Liberman, Waber and Cromer through selfconsistent field wave functions for all the atoms with relativistic correlations according to the Dirac equations. Waber and Cromer [8] calculated the theoretical atomic radii of a number of atoms through relativistic Hartree-Fock method. In absence of any experimental data [6] regarding the absolute size of atoms and ions the question of accuracy of any theoretical or experimental method of computing atomic or ionic size cannot be just tested. Sporadic informations of calculations of atomic size by sophisticated theoretical methods are found to appear in the literature but such data are mostly unpublished. Also it appears that such data has never been applied to compute any property of isolated atom or ion. In the premises, we propose a less sophisticated simple technique of computing theoretical or absolute radii of atoms and ions. The level of theory is semi-empirical. Slater [10] suggested an analytical form of the radial part of one-electron function that provides with a scope of computing a number of one-electron and radial properties including the scope of computation of theoretical atomic and ionic radii. The computation of theoretical atomic and ionic radii becomes tremendously simplified if Slater Orbitals are used in such calculation.

Slater [10] proposed a much simpler analytical form for the radial part of the one-electron function or orbital now widely known as Slater-type orbitals, STO's. The analytical form of normalized radial part of atomic orbital $R_{n l}(r)$ is given by,

$$
\mathrm{R}_{\mathrm{nl}}(\mathrm{r})=(2 \xi)^{\mathrm{n}+1 / 2}[(2 \mathrm{n}) !]^{-1 / 2} \mathrm{r}^{\mathrm{n}-1} \exp (-\xi \mathrm{r})
$$

Where, $\quad \mathrm{n}=$ the principal quantum number of the electron

$\mathrm{r}=$ distance from the nucleus

$\xi$ is the orbital exponent and is given by

$$
\xi=(\mathrm{Z}-\mathrm{S}) / \mathrm{n}^{*}
$$

Where, $\mathrm{Z}=$ atomic number and $\mathrm{S}$ is the screening constant and $\mathrm{n}^{*}$ is the effective principal quantum number. The quantity, $(Z-S)$ is further identified as effective nuclear charge, $Z^{*}$.

In terms of Slater orbitals the theoretical atomic or ionic radii,

$$
\mathrm{r}_{\max }=\mathrm{n} / \xi
$$

The eqn. (3) is the formula of computation of theoretical atomic and ionic radii in terms of Slater orbital. This shows that theoretical radii of atoms and ions can be easily computed only if $\xi$ is known and one can know $\xi$, if the effective principal quantum number of the outermost shell of the atom $\left(n^{*}\right)$ and the screening constant (S) are known. Although the SCF $\xi$ is also available [11], Slater [10] laid down a set of empirical rules for calculating $S$ and $n^{*}$ to give good approximations to the best atomic orbitals of this type. The goal of this work has been to explore the possibility of developing a simple but effective method of computing the absolute radii atoms and ions relying upon Slater's definition of absolute radii and using Slater's orbitals. It is well known that orbital exponent, $\xi$ obtained by Slater's 
empirical rules are found useful in SCF calculation giving satisfactory results although use of SCF optimized $\xi$ is simultaneously in use [11].

In the present venture we have computed the theoretical atomic radii of as many as 103 elements of the periodic table by semi-empirical method using Slater's orbital and involving Slater's empirical rule for the computation of $\xi$. Since there is no scope of comparing the atomic and ionic radii with the experimental values, we have tested the range of validity of calculated sizes in a number of ways. The periodicity exhibited by the computed radii is compared with the periodicity inherent in the periodic table. In order to explore the internal consistency between the calculated sizes and the size dependent properties of the atoms, a comparative study of size vis-a-vis the electronegativity and the experimental quantity like first ionization potential of the atoms is made. A comparative study of the relative magnitudes of the sizes of the atoms of present calculation and the radii published by other workers - both theoretical and experimental is also made. The computed theoretical radii are used to calculate a number of size dependent intrinsic physical properties of isolated atoms viz., (1) the diamagnetic part of magnetic susceptibility $\left(\chi_{\mathrm{dia}}\right)$ of 54 elements, and (2) the atomic polarizability $(\alpha)$, and (3) the global hardness $(\eta)$ of as many as 103 elements of the periodic table. We have compared such computed size dependent properties of the atoms with available results of such quantities.

\section{Method of Computation}

The radial charge density distribution function is defined $[5,12,13]$ as $4 \pi r^{2} R^{2}$ or simply $r^{2} R^{2}$ where $\mathrm{R}$ is the radial function. According to Slater [7], theoretical atomic radius is the maximum of the radial charge density distribution function of the topmost electron of the atom or ion.

Radial charge density distribution function $\rho(r)$ is given by

$$
\rho(r)=4 \pi r^{2} R^{2}
$$

Now, putting the normalized form of the $\mathrm{R}$ from the eqn.(1) into eqn.(4) we get

$$
\begin{aligned}
\rho(\mathrm{r}) & =4 \pi r^{2}(2 \xi)^{2 \mathrm{n}+1}[(2 \mathrm{n}) !]^{-1} \mathrm{r}^{2 \mathrm{n}-2} \exp (-2 \xi \mathrm{r}) \\
& =4 \pi \mathrm{r}^{2 \mathrm{n}}(2 \xi)^{2 \mathrm{n}+1}[(2 \mathrm{n}) !]^{-1} \exp (-2 \xi \mathrm{r})
\end{aligned}
$$

The parameters $n$ and $\xi$ are explained above.

Differentiating the left-hand side with respect to $r$, and equating the result with zero, we get the maximum of the radial charge density distribution function, the theoretical atomic radii,

$$
\mathrm{d} \rho(\mathrm{r}) / \mathrm{dr}=\left[4 \pi(2 \xi)^{2 \mathrm{n}+1}[(2 \mathrm{n}) !]^{-1} \exp (-2 \xi \mathrm{r})\right]\left[2 \mathrm{nr} \mathrm{r}^{2 \mathrm{n}-1}-2 \xi \mathrm{r}^{2 \mathrm{n}}\right]
$$

Equating the right hand side of the eqn. (6) equal to zero and replacing $r$ by $r_{\max }$, we obtain,

$$
\left(n r_{\max }^{2 n-1}-\xi r_{\max }^{2 n}\right)=0
$$

From which it follows that

$$
\mathrm{n} \mathrm{r}_{\max }^{-1}=\xi
$$

From this relation we obtain the formula for computing the theoretical atomic or ionic radii already noted in eqn (3) above, i.e. the theoretical atomic or ionic radii $r=r_{\max }$ 


$$
\mathrm{r}=\mathrm{n} / \xi
$$

the relevant quantities and parameters are defined above.

The screening constant (S) may be calculated from Slater's rule and are profusely available in any standard textbook of physical and inorganic chemistry. The values of $\mathrm{n}^{*}$ for principal quantum number $\mathrm{n}$ up to 6 and $\mathrm{Z}^{*}$ for about 26 elements are published by Pople [14]. For the rest of the atoms, $\mathrm{n}^{*}$ are calculated by simple extrapolation. and we have got the extrapolated value of $\mathrm{n}^{*}=4.3$ for principal quantum number 7 . The $\mathrm{Z}^{*}$ and $\xi$ for required atoms are calculated and for that matter we have relied upon the ground state electron-configuration published by Shriver and Atkins [15]. In this work we report the theoretical radii of atoms only. The calculated orbital exponents and atomic radii are shown in Table 1. The computed theoretical atomic radii are plotted as a function of atomic number in Figure 1 and Figure 2. To explore the effectiveness of the present method in exhibiting the well known

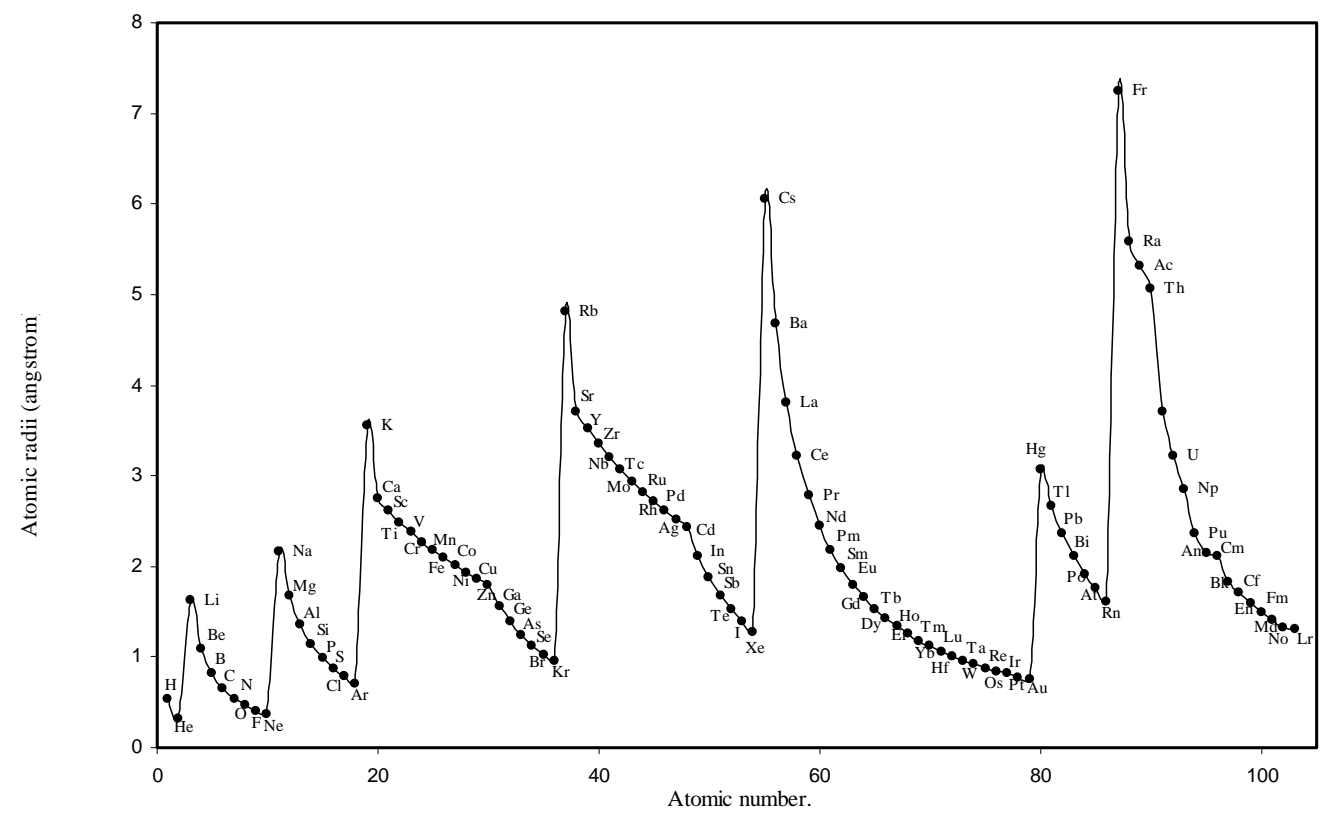

Figure 1. Plot of atomic radii (angstrom) as a function of atomic number.

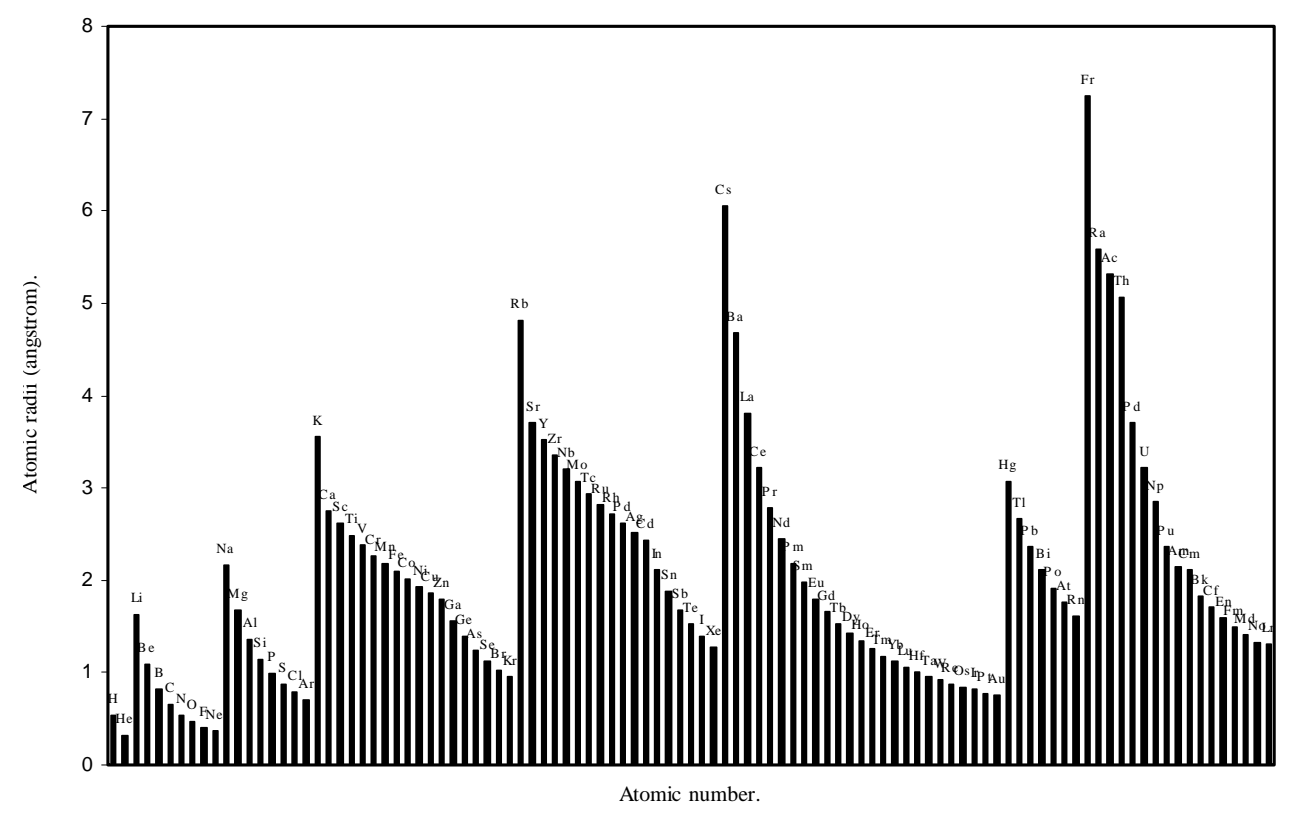

Figure 2. Plot of atomic radii (angstrom) as a function of atomic number. 
Table 1. Calculated orbital exponents $(\xi)$ and radii of atoms.

\begin{tabular}{|c|c|c|c|c|c|c|c|c|}
\hline Atoms & $\begin{array}{c}\text { Orbital } \\
\text { Exponent }\end{array}$ & $\begin{array}{c}\text { Atomic Radii } \\
(\AA)\end{array}$ & Atoms & $\begin{array}{c}\text { Orbital } \\
\text { Exponent }\end{array}$ & $\begin{array}{c}\text { Atomic Radii } \\
(\AA)\end{array}$ & Atoms & $\begin{array}{c}\text { Orbital } \\
\text { Exponent }\end{array}$ & $\begin{array}{c}\text { Atomic Radi } \\
(\AA)\end{array}$ \\
\hline $\mathrm{H}$ & 1 & 0.5292 & $\mathrm{Kr}$ & 2.2297 & 0.9493 & $\mathrm{Lu}$ & 3 & 1.0583 \\
\hline $\mathrm{He}$ & 1.7 & 0.3113 & $\mathrm{Rb}$ & 0.55 & 4.8106 & Hf & 3.15 & 1.0079 \\
\hline $\mathrm{Li}$ & 0.65 & 1.6282 & $\mathrm{Sr}$ & 0.7125 & 3.7135 & $\mathrm{Ta}$ & 3.3095 & 0.9594 \\
\hline $\mathrm{Be}$ & 0.975 & 1.0855 & $\mathrm{Y}$ & 0.75 & 3.5278 & $\mathrm{~W}$ & 3.4643 & 0.9165 \\
\hline $\mathrm{B}$ & 1.3 & 0.8141 & $\mathrm{Zr}$ & 0.7875 & 3.3598 & $\operatorname{Re}$ & 3.619 & 0.8773 \\
\hline $\mathrm{C}$ & 1.625 & 0.6513 & $\mathrm{Nb}$ & 0.825 & 3.2071 & Os & 3.7738 & 0.8413 \\
\hline $\mathrm{N}$ & 1.95 & 0.5427 & Mo & 0.8625 & 3.0677 & $\mathrm{Ir}$ & 3.9286 & 0.8182 \\
\hline $\mathrm{O}$ & 2.275 & 0.4652 & $\mathrm{Tc}$ & 0.9 & 2.9398 & $\mathrm{Pt}$ & 4.0833 & 0.7776 \\
\hline $\mathrm{F}$ & 2.6 & 0.4071 & $\mathrm{Ru}$ & 0.9375 & 2.8222 & $\mathrm{Au}$ & 4.2381 & 0.7492 \\
\hline $\mathrm{Ne}$ & 2.925 & 0.3618 & $\mathrm{Rh}$ & 0.975 & 2.7137 & $\mathrm{Hg}$ & 4.3929 & 3.0636 \\
\hline $\mathrm{Na}$ & 0.7333 & 2.1649 & $\mathrm{Pd}$ & 1.0125 & 2.6132 & $\mathrm{Tl}$ & 1.1905 & 2.667 \\
\hline $\mathrm{Mg}$ & 0.95 & 1.6711 & $\mathrm{Ag}$ & 1.05 & 2.5199 & $\mathrm{~Pb}$ & 1.3452 & 2.3603 \\
\hline $\mathrm{Al}$ & 1.1667 & 1.3607 & $\mathrm{Cd}$ & 1.0875 & 2.433 & $\mathrm{Bi}$ & 1.5 & 2.1167 \\
\hline $\mathrm{Si}$ & 1.3833 & 1.1476 & In & 1.25 & 2.1167 & Po & 1.6548 & 1.9187 \\
\hline $\mathrm{P}$ & 1.6 & 0.9922 & Sn & 1.4125 & 1.8732 & At & 1.8095 & 1.7546 \\
\hline S & 1.8167 & 0.8738 & $\mathrm{Sb}$ & 1.575 & 1.6799 & $\mathrm{Rn}$ & 1.9643 & 1.6164 \\
\hline $\mathrm{Cl}$ & 2.0333 & 0.7807 & $\mathrm{Te}$ & 1.7375 & 1.5228 & $\mathrm{Fr}$ & 0.5116 & 7.2404 \\
\hline $\mathrm{Ar}$ & 2.25 & 0.7056 & I & 1.9 & 1.3926 & $\mathrm{Ra}$ & 0.6628 & 5.5887 \\
\hline $\mathrm{K}$ & 0.5946 & 3.5598 & $\mathrm{Xe}$ & 2.0625 & 1.2828 & Ac & 0.6977 & 5.3091 \\
\hline $\mathrm{Ca}$ & 0.7703 & 2.7479 & Cs & 0.5238 & 6.0615 & Th & 0.7326 & 5.0569 \\
\hline $\mathrm{Sc}$ & 0.8108 & 2.6106 & $\mathrm{Ba}$ & 0.6786 & 4.6788 & $\mathrm{~Pa}$ & 1 & 3.7042 \\
\hline $\mathrm{Ti}$ & 0.8514 & 2.4861 & $\mathrm{La}$ & 0.8333 & 3.8102 & $\mathrm{U}$ & 1.1512 & 3.2177 \\
\hline $\mathrm{V}$ & 0.8919 & 2.3732 & $\mathrm{Ce}$ & 0.9881 & 3.2133 & $\mathrm{~Np}$ & 1.3023 & 2.8443 \\
\hline $\mathrm{Cr}$ & 0.9324 & 2.2701 & $\operatorname{Pr}$ & 1.1429 & 2.778 & $\mathrm{Pu}$ & 1.5698 & 2.3596 \\
\hline $\mathrm{Mn}$ & 0.973 & 2.1754 & $\mathrm{Nd}$ & 1.2976 & 2.4468 & $\mathrm{Am}$ & 1.7209 & 2.1525 \\
\hline $\mathrm{Fe}$ & 1.0135 & 2.0885 & $\mathrm{Pm}$ & 1.4524 & 2.1861 & $\mathrm{Cm}$ & 1.7558 & 2.1097 \\
\hline Co & 1.0541 & 2.008 & $\mathrm{Sm}$ & 1.6071 & 1.9756 & $\mathrm{Bk}$ & 2.0233 & 1.8308 \\
\hline $\mathrm{Ni}$ & 1.0946 & 1.9337 & $\mathrm{Eu}$ & 1.7619 & 1.802 & $\mathrm{Cf}$ & 2.1744 & 1.7035 \\
\hline $\mathrm{Cu}$ & 1.1351 & 1.8648 & $\mathrm{Gd}$ & 1.9167 & 1.6565 & En & 2.3256 & 1.5928 \\
\hline $\mathrm{Zn}$ & 1.1757 & 1.8004 & $\mathrm{~Tb}$ & 2.0714 & 1.5328 & Fm & 2.4767 & 1.4956 \\
\hline $\mathrm{Ga}$ & 1.3514 & 1.5663 & Dy & 2.2262 & 1.4262 & $\mathrm{Md}$ & 2.6279 & 1.4096 \\
\hline $\mathrm{Ge}$ & 1.527 & 1.3862 & Ho & 2.381 & 1.3335 & No & 2.7791 & 1.3329 \\
\hline As & 1.7027 & 1.2431 & $\mathrm{Er}$ & 2.5357 & 1.2521 & $\mathrm{Lr}$ & 2.814 & 1.3164 \\
\hline $\mathrm{Se}$ & 1.8784 & 1.1269 & $\mathrm{Tm}$ & 2.6905 & 1.1801 & & & \\
\hline $\mathrm{Br}$ & 2.0541 & 1.0305 & $\mathrm{Yb}$ & 2.8452 & 1.1159 & & & \\
\hline
\end{tabular}

$\mathrm{d}$-block and f-block contractions in the periodic table, the computed radii of $3 \mathrm{~d}, 4 \mathrm{~d}, 4 \mathrm{f}$ and $5 \mathrm{f}$ elements are separately plotted as a function of the atomic numbers in Figs. 3, 4, 5, and 6, respectively. The methods of computation of absolute size dependent physical properties like (A) the diamagnetic part of magnetic susceptibilities $\left(\chi_{\mathrm{dia}}\right)$, (B) atomic polarizabilities $(\alpha)$, and $(C)$ the global hardness $(\eta)$ are stated below. 


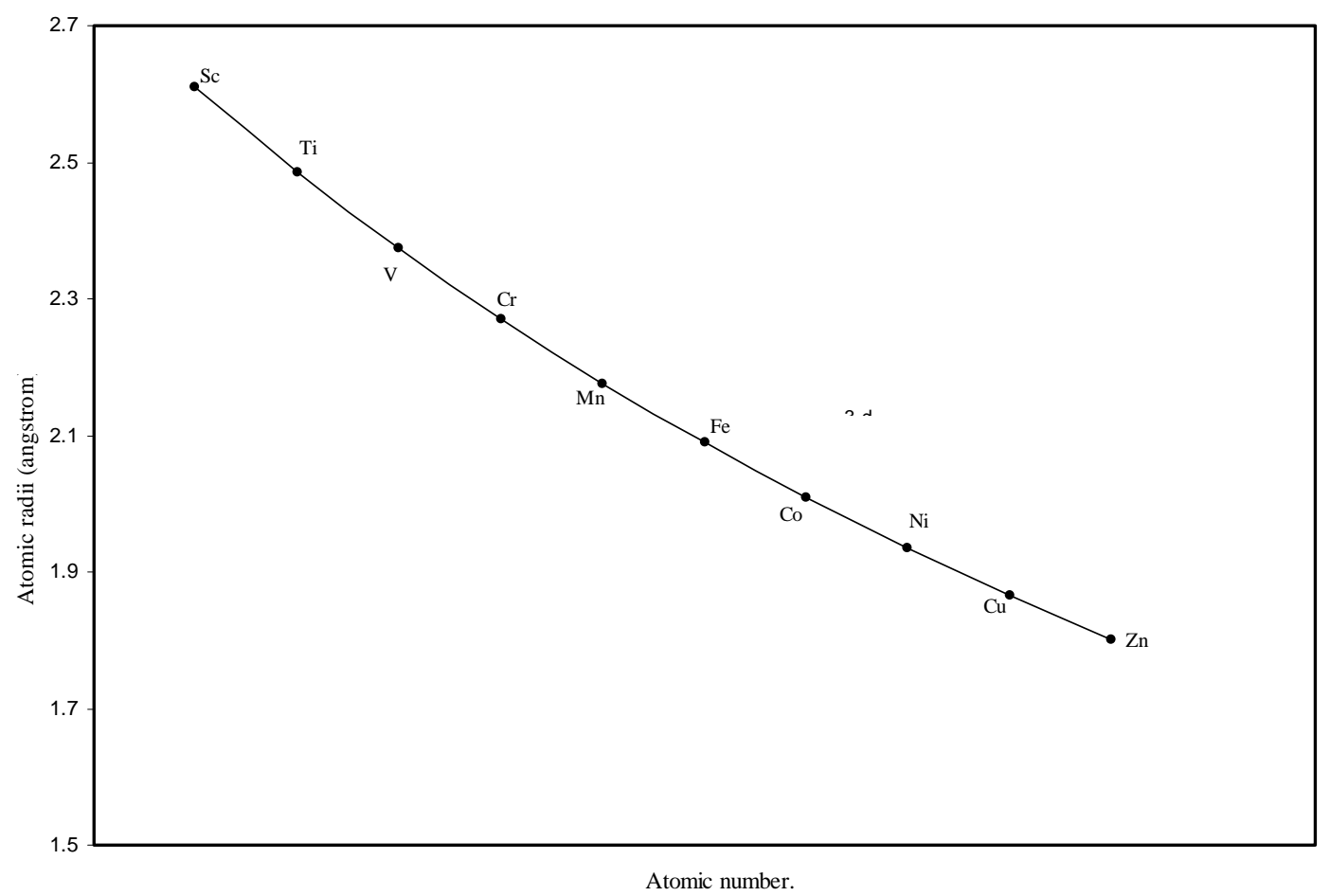

Figure 3. Plot of atomic radii of first transition sereis (3-d block) elements in angstrom unit as a function of atomic number.

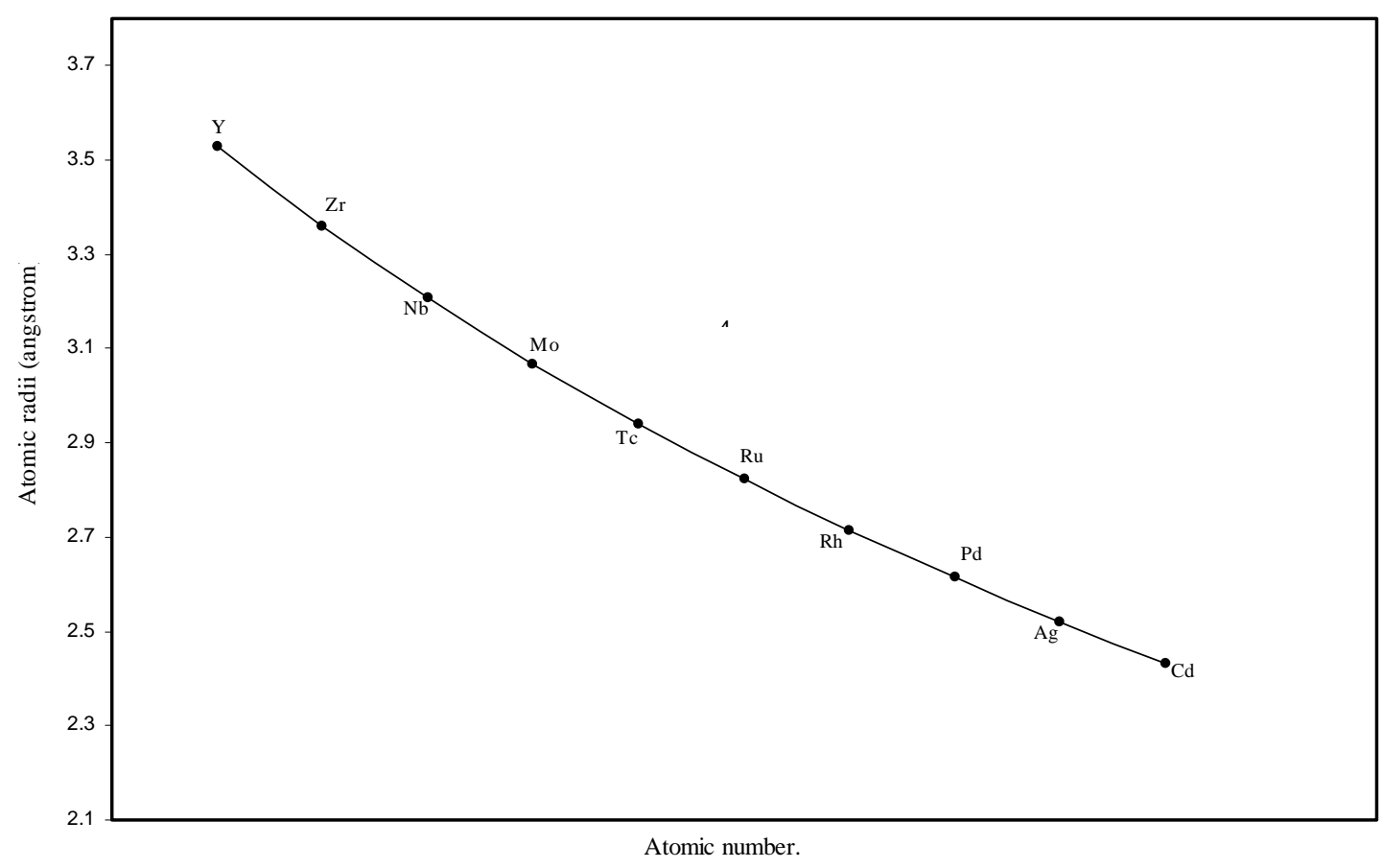

Figure 4. Plot of atomic radii of second transition series (4-d block) elements in angstrom unit as a function of atomic number. 


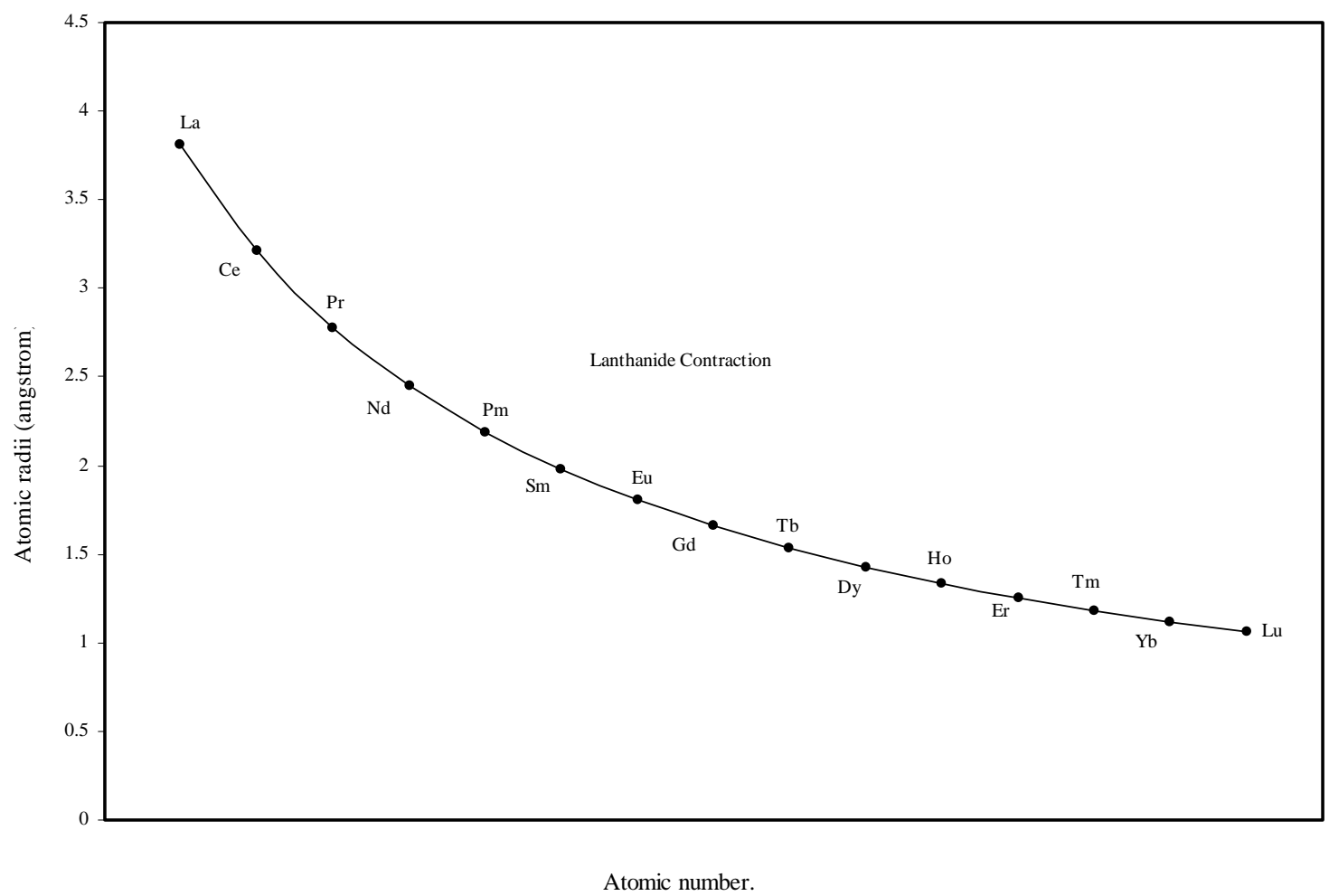

Figure 5. Plot of atomic radii of lanthanides in angstrom unit as function of atomic number.

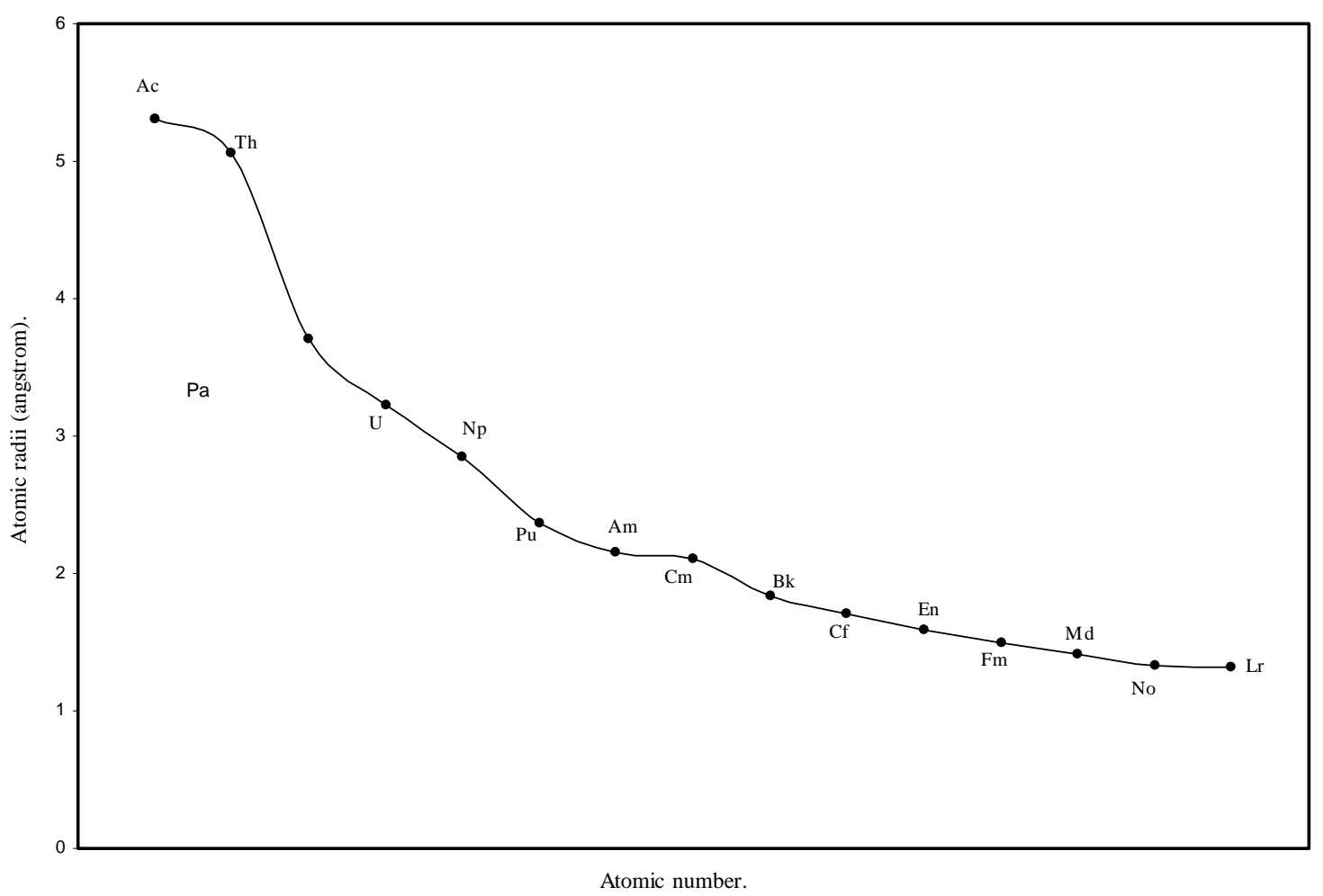

Figure 6. Plot of atomic radii of actinides in angstrom unit as a function of Atomic number.

\section{(A) Diamagnetic part of magnetic susceptibility, $\chi_{\text {dia }}$.}

The theoretical determination of atomic and ionic radii provides with a scope of a theoretical calculation of the diamagnetic part of the atomic susceptibility, which occurs even when an atom already has a permanent moment. We have computed the diamagnetic susceptibility of as many as 54 elements starting from hydrogen. Since atoms after element with atomic number 54 are strongly 
paramagnetic due to L-S coupling, the computation of diamagnetic susceptibility of atoms of such elements is not taken up.

The induced diamagnetic moment of an atom is opposite to the applied field and is proportional to the square of the orbit radius. The classical equation of diamagnetic susceptibility of atom [16,17] per mole is given by

$$
\chi_{\text {dia }}=-2.84 \times 10^{-10} \Sigma_{\mathrm{n}}\left\langle\mathrm{r}^{2}\right\rangle_{\mathrm{av}}
$$

Where, $\left\langle\mathrm{r}^{2}\right\rangle_{\mathrm{av}}$ is the mean square of the actual orbital radius or the average of the square of all the orbit radii and $\Sigma$ implies the summation of $\left\langle\mathrm{r}^{2}\right\rangle_{\text {av }}$ for all $\mathrm{n}$ electrons in atom as the total moment is given by the sum over all the electrons in the atom.

There can not be any experimental value for $\Sigma_{\mathrm{n}}\left\langle\mathrm{r}^{2}\right\rangle_{\text {av }}$ of an atom as such and quantum mechanics can compute it and it is interpreted as the average of the square of the distance from the center for the probability distribution [18]. However, it is mentioned that a slight modification of the formula (8) by replacing the pre-factor of the RHS by 1.888 in place of 2.84 gives better result [19]. The modified formula is

$$
\chi_{\text {dia }}=-1.888 \times 10^{-10} \Sigma_{\mathrm{n}}\left\langle\mathrm{r}^{2}\right\rangle_{\mathrm{av}}
$$

We have calculated the $\left\langle\mathrm{r}^{2}\right\rangle_{\text {av }}$ of each atom by calculating the radii of each orbital. We have computed the $\left\langle\mathrm{r}^{2}\right\rangle_{\mathrm{av}}$ for all the 54 elements. With these values of $\left\langle\mathrm{r}^{2}\right\rangle_{\mathrm{av}}$, the molar diamagnetic susceptibility is computed through eqn.(9). The calculated $\left\langle\mathrm{r}^{2}\right\rangle_{\text {av }}$ and $\chi_{\text {dia }}$ are shown in Table 2. The computed values of $\left\langle\mathrm{r}^{2}\right\rangle_{\mathrm{av}}$ and $\chi_{\text {dia }}$ are plotted as a function of atomic number in Fig.7.

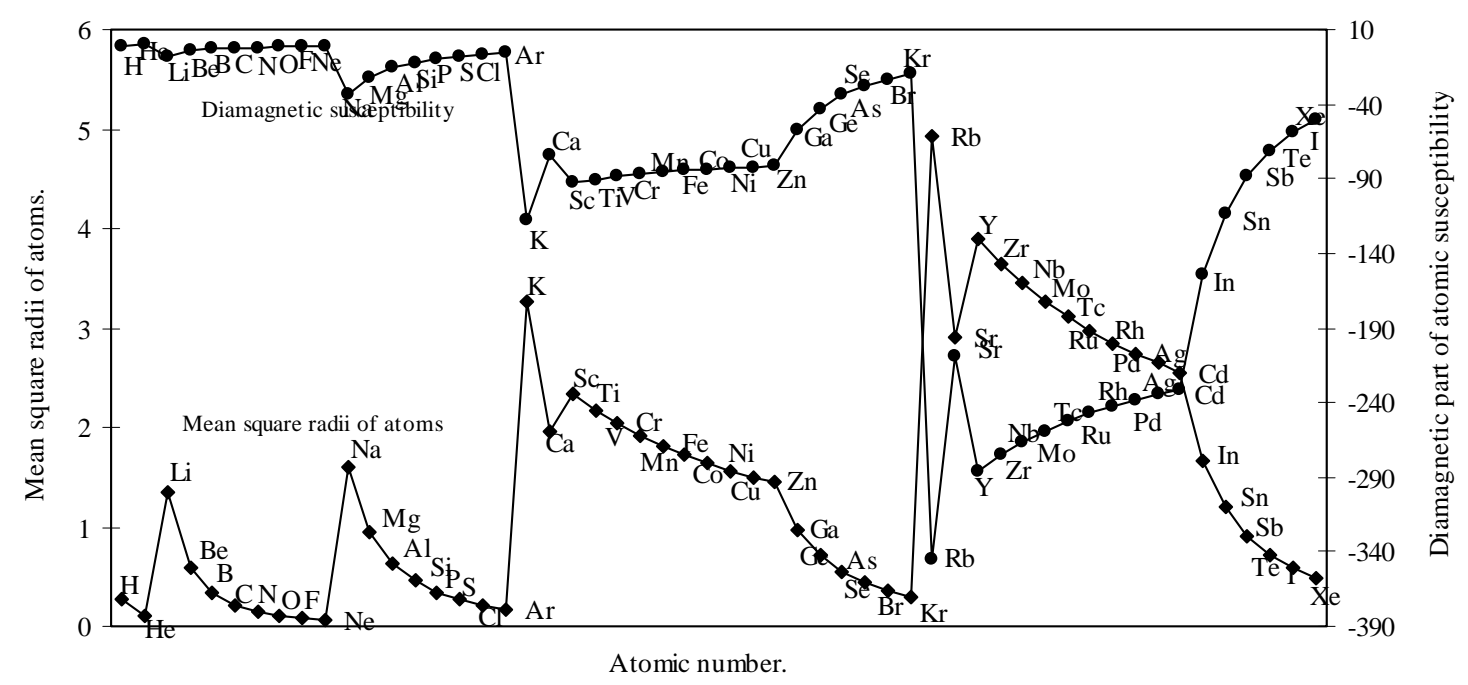

Figure 7. Plot of mean square radii and diamagnetic part of magnetic susceptibility of atoms as a function of atomic number.

\section{(B) Atomic polarizability, $\alpha$.}

One more important size dependent physical property of the atoms is the atomic polarizability, $\alpha$. By polarizability, Pearson [20] meant the ease of deforming the valance electron cloud of a chemical species. A closely related experimental quantity is electric dipole polarizability, $\alpha$, which actually 
Table 2. Computed mean square radii, $\left\langle\mathrm{r}^{2}\right\rangle$ and diamagnetic part of atomic susceptibility, $\left(\chi_{\mathrm{dia}}\right)$ of atoms.

\begin{tabular}{|c|c|c|c|c|c|}
\hline Atom & $<\mathrm{r}^{2}>\mathrm{X} 10^{-16}$ sq.cm & $\chi_{\operatorname{dia} \times 10^{-6}} \mathrm{c.c}$ & Atoms & $<\mathrm{r}^{2}>\mathrm{X} 10^{-16}$ sq.cm & $\chi_{\text {dia } \times 10^{-6}}$ c.c \\
\hline $\mathrm{H}$ & 0.2801 & -0.5287 & $\mathrm{Ni}$ & 1.5669 & -82.8339 \\
\hline $\mathrm{He}$ & 0.0969 & -0.3659 & $\mathrm{Cu}$ & 1.5013 & -82.2003 \\
\hline $\mathrm{Li}$ & 1.3447 & -7.6165 & $\mathrm{Zn}$ & 1.4422 & -81.6834 \\
\hline $\mathrm{Be}$ & 0.5994 & -4.5267 & $\mathrm{Ga}$ & 0.9694 & -56.7355 \\
\hline B & 0.3377 & -3.1882 & Ge & 0.7087 & -42.8176 \\
\hline C & 0.2164 & -2.4513 & As & 0.5452 & -33.912 \\
\hline $\mathrm{N}$ & 0.1504 & -1.9872 & $\mathrm{Se}$ & 0.4345 & -27.8915 \\
\hline $\mathrm{O}$ & 0.1106 & -1.6698 & $\mathrm{Br}$ & 0.3553 & -23.4787 \\
\hline $\mathrm{F}$ & 0.0847 & -1.4395 & $\mathrm{Kr}$ & 0.2965 & -20.1491 \\
\hline $\mathrm{Ne}$ & 0.0669 & -1.264 & $\mathrm{Rb}$ & 4.9346 & -344.7138 \\
\hline $\mathrm{Na}$ & 1.5972 & -33.1713 & $\mathrm{Sr}$ & 2.9131 & -208.9958 \\
\hline $\mathrm{Mg}$ & 0.9558 & -21.6546 & Y & 3.8844 & -286.0142 \\
\hline $\mathrm{Al}$ & 0.6368 & -15.6297 & $\mathrm{Zr}$ & 3.6483 & -275.519 \\
\hline $\mathrm{Si}$ & 0.4549 & -12.0238 & $\mathrm{Nb}$ & 3.444 & -266.593 \\
\hline $\mathrm{P}$ & 0.3413 & -9.6652 & Mo & 3.266 & -258.9836 \\
\hline$S$ & 0.2655 & -8.0205 & $\mathrm{Tc}$ & 3.1099 & -252.4745 \\
\hline $\mathrm{Cl}$ & 0.2125 & -6.8214 & $\mathrm{Ru}$ & 2.9723 & -246.9151 \\
\hline $\mathrm{Ar}$ & 0.1741 & -5.915 & $\mathrm{Rh}$ & 2.8505 & -242.1745 \\
\hline $\mathrm{K}$ & 3.2677 & -117.2196 & $\mathrm{Pd}$ & 2.7419 & -238.1305 \\
\hline $\mathrm{Ca}$ & 1.9664 & -74.2518 & $\mathrm{Ag}$ & 2.6448 & -234.6907 \\
\hline $\mathrm{Sc}$ & 2.338 & -92.6958 & $\mathrm{Cd}$ & 2.5577 & -231.7906 \\
\hline $\mathrm{Ti}$ & 2.1789 & -90.5027 & In & 1.6726 & -154.7359 \\
\hline $\mathrm{V}$ & 2.0413 & -88.6433 & $\mathrm{Sn}$ & 1.2015 & -113.4178 \\
\hline $\mathrm{Cr}$ & 1.9214 & -87.0608 & $\mathrm{Sb}$ & 0.9035 & -87.9572 \\
\hline $\mathrm{Mn}$ & 1.8158 & -85.7077 & $\mathrm{Te}$ & 0.7218 & -70.8638 \\
\hline $\mathrm{Fe}$ & 1.723 & -84.5766 & I & 0.5866 & -58.7022 \\
\hline Co & 1.6403 & -83.6167 & $\mathrm{Xe}$ & 0.4872 & -49.6685 \\
\hline
\end{tabular}

describes the linear response of the electron cloud of a chemical species to an external field much lower than what would be needed to ionize the system. The static electric dipole polarizability $\alpha$ can be determined theoretically and experimentally in various ways.

The induced dipole moment in an atom or molecule is proportional to the applied electric field [13] and the necessary formula can be written as

$$
\mathbf{d}=\alpha \mathbf{F}
$$

where, $\mathbf{F}=$ the applied electric field, $\mathbf{d}=$ induced dipole moment, and $\alpha$ is the constant of proportionality and is called polarizability.

It has been shown [21] that the polarizability $\alpha$ of a conducting sphere of radius $r$ is equal to $r^{3}$.

$$
\alpha=\mathrm{r}^{3}
$$

And in terms of its volume $\mathrm{V}$, the same formula looks like

$$
\alpha=3 \mathrm{~V} / 4 \pi
$$

where

$$
\mathrm{V}=4 / 3 \pi \mathrm{r}^{3}
$$


The generality of linear volume-polarizability has been assessed [21] quantum mechanically in case of atoms. Although the formula for the polarizability has been laid down in eqn (11), it is suggested that, due to inhomogeneity of the electron cloud, the actual formula [22] should be

$$
\alpha=\mathrm{Kr}^{3}
$$

where, $\mathrm{K}$ is the proportionality constant.

For atoms, the value of ' $\mathrm{K}$ ' was determined by Dimitrieva and Plindov [23] by 'Atomic Oscillation Theory' as 0.585. Dutta and Hati [22] used the value of $K=0.792$ which is the arithmetic average of 1 and the value of Dimitrieva and Plindov [23]. But the exact quantum mechanical calculation [19] of polarizability of hydrogen atom derives the formula

$$
\alpha=(9 / 2) \mathrm{a}_{0}{ }^{3}
$$

where $\mathrm{a}_{0}$ is the Bohr radius.

Comparing eqns. (14) and (15) we see that $K=4.5$

Relying more upon the quantum mechanical derivation [19] of the atomic polarizability, we see that, the proportional constant $\mathrm{K}$ in eqn.(14) is neither 1 nor less than 1 , but it is equal to 4.5 for hydrogen atom. In absence of any other reliable value of ' $K$ ', the proportionality constant, we have first tried to obtain an optimized the proportionality constant $\mathrm{K}$. We first computed the atomic polarizability of as much as 8 elements whose experimental polarizabilities are quoted by Purcell in reference [19] using the above quantum mechanical value of $K=4.5$. We find that the calculated values of atomic polarizability of eight elements with $\mathrm{K}=4.5$ through the theoretical atomic radii are close to the experimental values quoted by Purcell [19]. We have, therefore, computed the atomic polarizabilities of the rest of the elements with the same value of the proportionality constant $K=4.5$. The computed atomic polarizability of all the 103 elements are shown in Table 3. We have plotted the theoretically computed atomic polarizability as a function of atomic number in Figure 8.

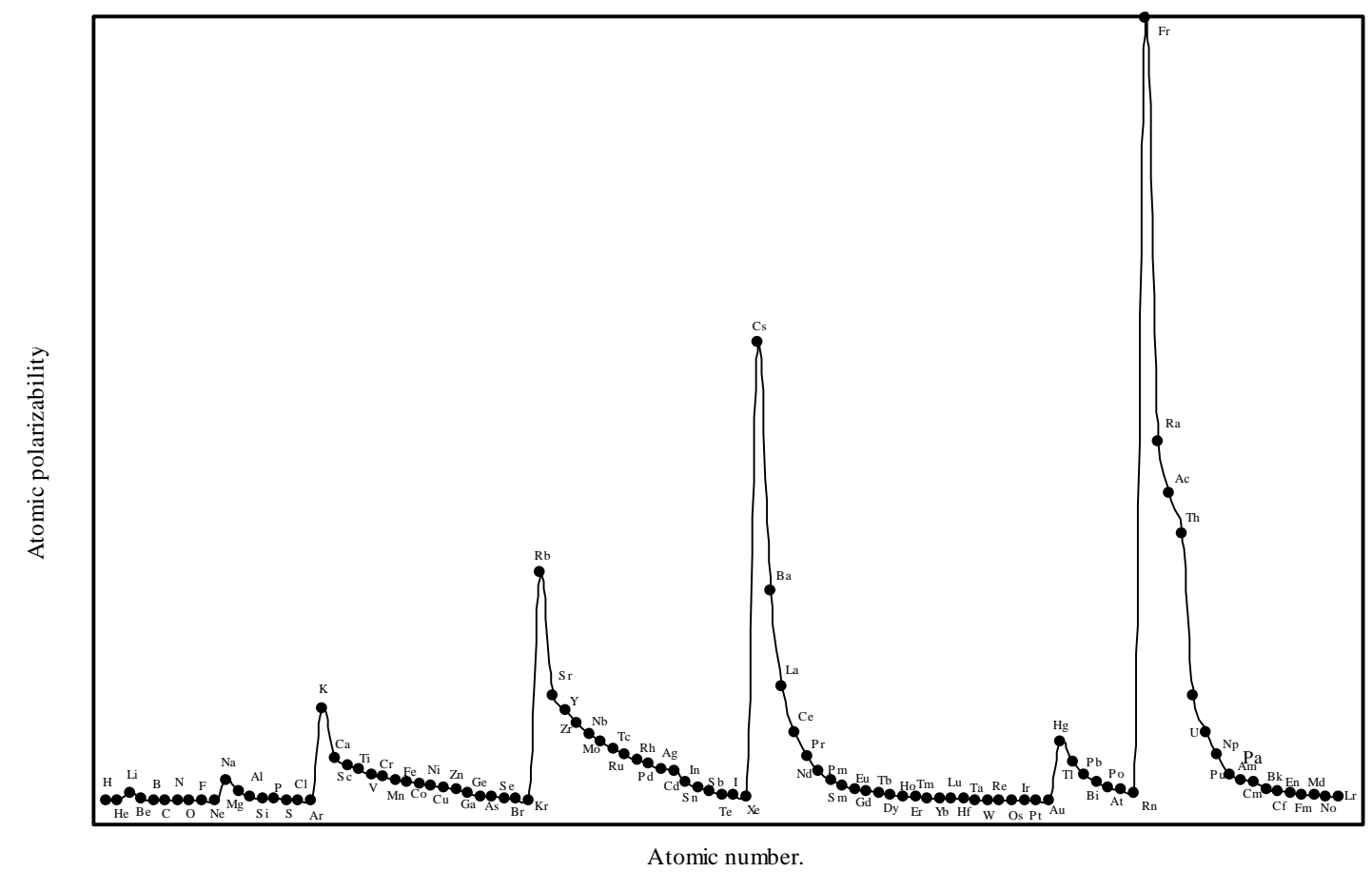

Figure 8. Plot of atomic polarizability (c.c) as a function of atomic number. 
Table 3. Computed atomic polarizability ( $\alpha$ ) and global hardness $(\eta)$ of atoms.

\begin{tabular}{|c|c|c|c|c|c|c|c|c|}
\hline Atoms & $\alpha \times 10^{-24}$ c.c & $\eta(\mathbf{e v})$ & Atoms & $\alpha \times 10^{-24}$ c.c & $\eta(\mathrm{ev})$ & Atoms & $\alpha \times 10^{-24}$ c.c & $\eta(\mathbf{e v})$ \\
\hline $\mathrm{H}$ & 0.6669 & 13.588 & $\mathrm{Kr}$ & 3.8497 & 7.5748 & $\mathrm{Lu}$ & 5.3338 & 6.7947 \\
\hline $\mathrm{He}$ & 0.1358 & 22.383 & $\mathrm{Rb}$ & 500.9683 & 1.4948 & $\mathrm{Hf}$ & 4.6075 & 7.1344 \\
\hline $\mathrm{Li}$ & 19.4239 & 4.4164 & $\mathrm{Sr}$ & 230.4462 & 1.9364 & $\mathrm{Ta}$ & 3.9739 & 7.4951 \\
\hline $\mathrm{Be}$ & 5.7558 & 6.6244 & $\mathrm{Y}$ & 197.5715 & 2.0383 & $\mathrm{~W}$ & 3.4643 & 7.8459 \\
\hline B & 2.428 & 8.8328 & $\mathrm{Zr}$ & 170.6683 & 2.1402 & $\operatorname{Re}$ & 3.0385 & 8.1965 \\
\hline $\mathrm{C}$ & 1.2432 & 11.0407 & $\mathrm{Nb}$ & 148.4397 & 2.2422 & Os & 2.6796 & 8.5472 \\
\hline $\mathrm{N}$ & 0.7193 & 13.25 & Mo & 129.9126 & 2.344 & $\mathrm{Ir}$ & 2.3756 & 8.8973 \\
\hline $\mathrm{O}$ & 0.453 & 15.4574 & $\mathrm{Tc}$ & 114.3315 & 2.446 & $\mathrm{Pt}$ & 2.1175 & 9.2474 \\
\hline $\mathrm{F}$ & 0.3034 & 17.6634 & $\mathrm{Ru}$ & 101.1523 & 2.5479 & $\mathrm{Au}$ & 1.8924 & 9.598 \\
\hline $\mathrm{Ne}$ & 0.2131 & 19.875 & $\mathrm{Rh}$ & 89.9286 & 2.6498 & $\mathrm{Hg}$ & 129.646 & 2.3456 \\
\hline $\mathrm{Na}$ & 45.659 & 3.3215 & $\mathrm{Pd}$ & 80.3028 & 2.7517 & $\mathrm{Tl}$ & 85.3653 & 2.6962 \\
\hline $\mathrm{Mg}$ & 21 & 4.303 & $\mathrm{Ag}$ & 72.005 & 2.8536 & $\mathrm{~Pb}$ & 59.1717 & 3.0466 \\
\hline $\mathrm{Al}$ & 11.337 & 5.2846 & $\mathrm{Cd}$ & 64.8095 & 2.9555 & $\mathrm{Bi}$ & 42.6767 & 3.3972 \\
\hline $\mathrm{Si}$ & 6.8011 & 6.2659 & In & 42.6767 & 3.3972 & Po & 31.7858 & 3.7477 \\
\hline $\mathrm{P}$ & 4.3955 & 7.2473 & $\mathrm{Sn}$ & 29.5777 & 3.8388 & At & 24.3079 & 4.0983 \\
\hline S & 3.0023 & 8.2293 & $\mathrm{Sb}$ & 21.3335 & 4.2805 & $\mathrm{Rn}$ & 19.0046 & 4.4487 \\
\hline $\mathrm{Cl}$ & 2.1412 & 9.2107 & $\mathrm{Te}$ & 15.8906 & 4.7221 & Fr & 1705 & 0.9913 \\
\hline $\mathrm{Ar}$ & 1.5808 & 10.191 & I & 12.1532 & 5.0636 & $\mathrm{Ra}$ & 785.4977 & 1.2867 \\
\hline $\mathrm{K}$ & 202.9969 & 2.02 & $\mathrm{Xe}$ & 9.4993 & 5.6056 & Ac & 673.4033 & 1.3544 \\
\hline $\mathrm{Ca}$ & 93.3717 & 2.6162 & Cs & 1002.1964 & 1.1863 & Th & 581.6815 & 1.4222 \\
\hline $\mathrm{Sc}$ & 80.0633 & 2.7545 & $\mathrm{Ba}$ & 460.9098 & 1.5369 & $\mathrm{~Pa}$ & 228.7156 & 1.9413 \\
\hline $\mathrm{Ti}$ & 69.1712 & 2.8924 & $\mathrm{La}$ & 248.9177 & 1.8873 & $\mathrm{U}$ & 149.9164 & 2.2348 \\
\hline $\mathrm{V}$ & 60.1472 & 3.03 & $\mathrm{Ce}$ & 149.2883 & 2.2378 & $\mathrm{~Np}$ & 103.5473 & 2.5281 \\
\hline $\mathrm{Cr}$ & 52.6438 & 3.1676 & $\operatorname{Pr}$ & 96.4738 & 2.5885 & $\mathrm{Pu}$ & 59.1266 & 3.0473 \\
\hline $\mathrm{Mn}$ & 46.3265 & 3.3055 & $\mathrm{Nd}$ & 65.9186 & 2.9389 & $\mathrm{Am}$ & 44.8789 & 3.3407 \\
\hline $\mathrm{Fe}$ & 40.9939 & 3.443 & $\mathrm{Pm}$ & 47.0135 & 3.2893 & $\mathrm{Cm}$ & 42.2547 & 3.4084 \\
\hline Co & 36.4555 & 3.5811 & $\mathrm{Sm}$ & 34.6984 & 3.6398 & $\mathrm{Bk}$ & 27.5918 & 3.9277 \\
\hline $\mathrm{Ni}$ & 32.5372 & 3.7187 & $\mathrm{Eu}$ & 26.3316 & 3.9905 & $\mathrm{Cf}$ & 22.2453 & 4.2212 \\
\hline $\mathrm{Cu}$ & 29.1769 & 3.8561 & Gd & 20.4544 & 4.341 & En & 18.1843 & 4.5146 \\
\hline $\mathrm{Zn}$ & 26.2615 & 3.994 & $\mathrm{~Tb}$ & 16.2057 & 4.6913 & $\mathrm{Fm}$ & 15.0542 & 4.808 \\
\hline $\mathrm{Ga}$ & 17.2917 & 4.5909 & Dy & 13.0543 & 5.0419 & Md & 12.6038 & 5.1013 \\
\hline $\mathrm{Ge}$ & 11.9864 & 5.1874 & Ho & 10.6707 & 5.3924 & No & 10.6563 & 5.3949 \\
\hline As & 8.6443 & 5.7846 & Er & 8.8334 & 5.743 & $\mathrm{Lr}$ & 10.2631 & 5.4629 \\
\hline $\mathrm{Se}$ & 6.4397 & 6.381 & $\mathrm{Tm}$ & 7.3955 & 6.0934 & & & \\
\hline $\mathrm{Br}$ & 4.9244 & 6.978 & $\mathrm{Yb}$ & 6.253 & 6.4439 & & & \\
\hline
\end{tabular}

\section{(C) Global Hardness, $\eta$.}

The term hardness, $\eta$, as applied to atoms and molecules has no reference to its mechanical physical hardness [24]. We are concerned here about the chemical hardness of atoms. The definition of hardness has evolved with time from qualitative concept to the rigorous quantum mechanical definition [20]. The concept of hardness was first introduced by Mulliken [25] and formalized as a 
qualitative thumb rule of chemical reactivity known as HSAB principle by Pearson [20]. Using the Density Functional Theory (DFT) as basis, the qualitative HSAB principle of Pearson [20] was placed on a quantum mechanical basis by Parr, Pearson and others [26-30]. In terms of Density Functional Theory, the qualitative idea of hardness and softness was quantified and the terms 'hardness' and 'softness' were identified as fundamental theoretical parameters. Although the hardness was rigorously defined in terms of the Density Functional Theory, the operational and approximate definition for the purpose of computation was also suggested as follows [27-28,30].

The operational definition of hardness, $\eta$

$$
\eta=(\mathrm{I}-\mathrm{A}) / 2
$$

where, $\quad \eta=$ the global hardness of atoms or molecules

$\mathrm{I}=$ the ionization potential of atoms or molecules.

$\mathrm{A}=$ the electron affinity of atoms or molecules.

But in case of atoms, Pearson [31] pointed out that a simple formula of computing hardness of atoms could be derived from simple electrostatic considerations using atomic size. Dutta and Hati [22] have used the formula derived by Pearson to calculate the global hardness of a series of atoms. The only needed quantity for computing global hardness of atoms is the atomic radius. We therefore venture to use the atomic radii for the instant calculation to compute the global hardness $\eta$ of atoms. We have derived the formula for computing the global hardness of atoms as follows:

The energy, E (q) of charging a conducting sphere of radius $\mathrm{R}$ with charge $\mathrm{q}$ is classically given by [18]

$$
\begin{aligned}
E(q) & =q^{2} /\left(4 \pi \varepsilon_{0}\right) 2 R \\
& =q^{2} / 2 R
\end{aligned}
$$

( C. G. S. Unit).

where, $\mathrm{q}=$ charge and $\mathrm{R}=$ radius.

The implication of the eqn (18) is that the $\mathrm{E}(\mathrm{q})$ is the energy in ergs, $\mathrm{q}$ is the charge in electrostatic unit and $\mathrm{R}$ should be measured in $\mathrm{cm}$. Now increasing q by one unit and decreasing q by one unit, we get the changes in energy which are I and A, the ionization potential and electron affinity of atom respectively.

Now in e.s.u, the one unit of charge, which is associated with the process of ionization I, and the electron affinity A, should be e, the electronic charge. Hence,

$$
\begin{aligned}
& I=(q+e)^{2} / 2 R-q^{2} / 2 R \\
& A=q^{2} / 2 R-(q-e)^{2} / 2 R
\end{aligned}
$$

Since, the global hardness of atoms $\eta=1 / 2(\mathrm{I}-\mathrm{A})$

$$
\text { Or, } \quad \eta=\mathrm{e}^{2} / 2 \mathrm{R}
$$

where, $\mathrm{e}=$ the electronic charge in e.s.u.

But the formula derived by Pearson [31] looks a bit different from the formula in eqn. (19).

We have computed the global hardness of atoms, $\eta$, through eqn (19) and ultimately it is converted to electron volt $(\mathrm{eV})$. The theoretically computed values of global hardness of as many as 103 atoms 
are tabulated in Table 3. We have plotted the global hardness of atoms as a function of atomic number in Figure 9.

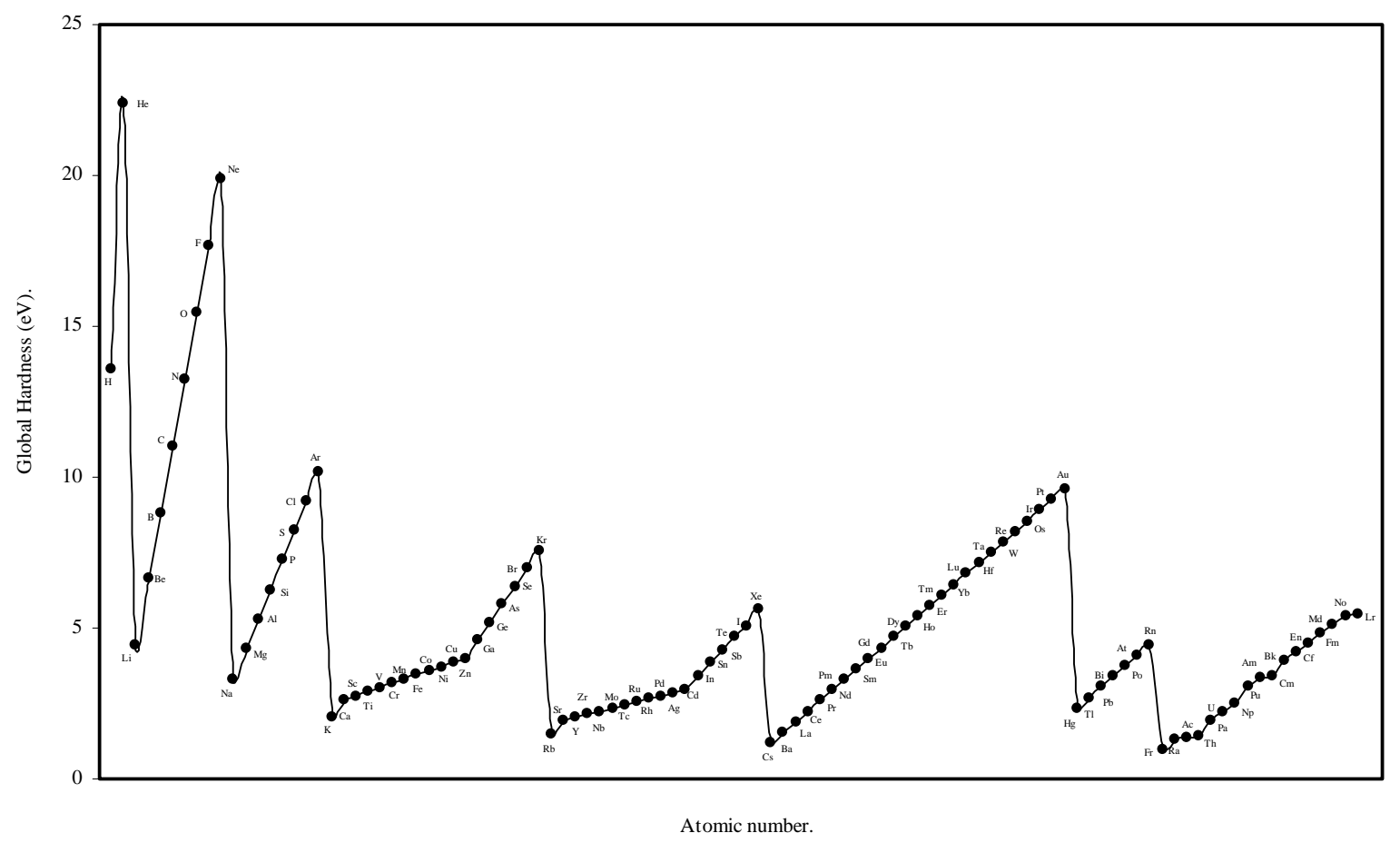

Figure 9. Plot of Global hardness $(\mathrm{eV})$ of atoms as a function of atomic number.

\section{Results and Discussions.}

The test of Periodicity of the sizes, and a comparative study of the radii of present calculation vis-a-vis other available data on the sizes of atoms.

The periodicity of elements, along with Darwin's theory of evolution and Planck's quantum theory, ranks as one of the greatest generalizations in Science [32,33]. Periodicity of atomic and ionic size is of utmost importance in chemistry. The phenomenon of contraction of the atomic size among the transition metals, lanthanides and actinides are some important periodic relationship of chemistry. However, a general trend of atomic size that has to be followed in a row and group of periodic table is already laid down [34] and stated as follows:

i) Atomic and ionic size decreases along the row.

ii) Atomic and ionic size increases down the main group.

iii) There is d-block contraction.

iv) There is f-block contraction.

v) The periodicity of atomic size should be isomorphic with the periodicity of ionization potential.

vi) The periodicity of size should be matched with the periodicity of electronegativity

The size relationship as a function of vertically downward or horizontally rightward movement will be straightforward if the sizes of the atoms are extrapolated as a function of atomic number. We have drawn the sizes of atoms as a function of atomic numbers in two different fashions in Figs. 1 and 2. It 
is distinctly evident that the curve 1 is isomorphic with the periodic curve of Lother Meyer. The general features of vertically downward expansion of size in a group and the horizontal contraction along a period is more distinct in Fig. 2. From a close examination of the nature of the profiles in Figs. 1 and 2 it is evident that the general pattern of size variation exhibited by the computed atomic radii as a function of atomic number conform to the basic demand of periodic law regarding the periodicity of atomic volumes. The general appearance of curves in Figs 3 and 4 show that the d-block contraction is distinct in the computed atomic radii. A close looks at the Figs. 5 and 6 reveals that the f-block contraction is distinctly manifest in the computed sizes of the atoms of lanthanides and actinides. Thus we see that the calculated sizes of atoms faithfully observe the periodic law and reproduce the periodic table.

Thereafter, in order to explore a correlation between the computed atomic size with the absolute periodic properties of atoms we now examine the nature of the curves of the first ionization potential and the electronegativities drawn as a function of atomic number in Figs 10 and 11 respectively. The correlation between the ionization potential and the size of the atoms is so reliable that Arhen's ${ }^{35}$ method utilized the regularities of the curve found by plotting radii vs. ionization potential for the determination of atomic radii of elements from graphical extrapolation.

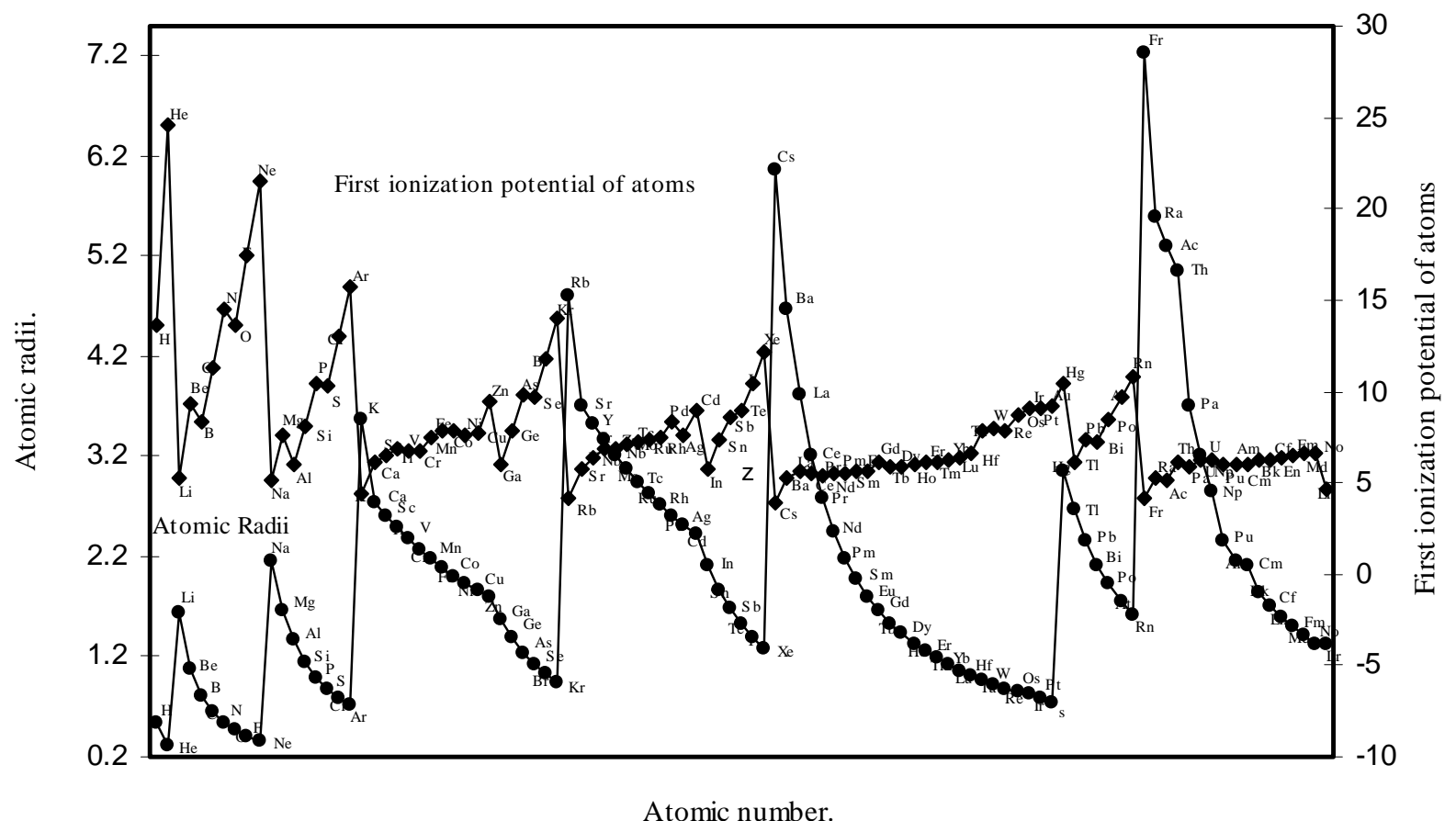

Figure 10. Plot of atomic radii and first ionization potential of atoms as a function of atomic number.

A close look at the figure 10 reveals that the ionization potential profile is just maintaining the inverse periodic relation with the atomic size curve and the two curves are homomorphic. It transpires from the nature of the profiles of the atomic radii and the ionization potential that the calculated atomic radii have a good correlation with the experimentally determined size dependent absolute property, the ionization potential. In Fig.11 the Pauling electronegativity $[2,15]$ of as many as 35 elements and their 


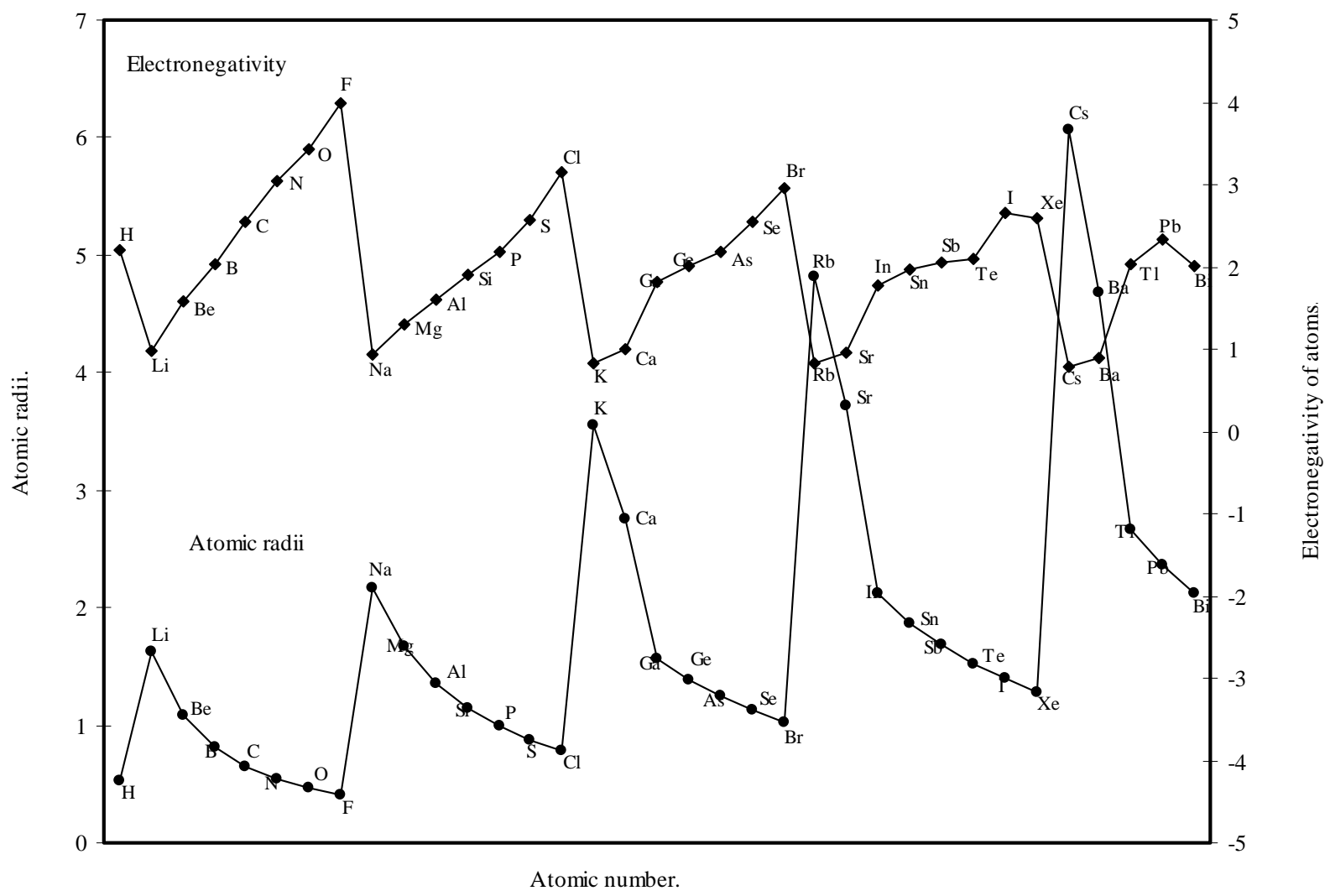

Figure 11. Plot of atomic radii and electronegativity of atoms as a function of atomic number.

theoretical atomic radii are plotted as function of atomic number. Although the electronegativity is an atomic property and depends upon the atomic radii [36], it is not a directly measurable experimental quantity of an isolated atom and it has no quantum mechanical operator [6,37]. But the inverse relationship between the polarizability and hardness is well established [38]. The inverse relationship between the polarizability and the electronagativity is also suggested [6]. From an analysis of the evident mutual inter-relationship between $\eta, \alpha$ and electronegativity and their relation with atomic radii, the inverse relationship between electronegativity and atomic size is self-evident. It is evident from Fig.11 that the profile for atomic size and the profile for electronegativity are both periodic and mutually homomorphic. Thus it is evident that the calculated sizes of the atoms have a good correlation with the electronegativity, and the experimental quantity like ionization potential.

To make a comparative study of the theoretical radii vis-à-vis the so called experimental radii, we have chosen the experimental values of Pauling [2] and have tabulated the radii of as many as 47 atoms forming crystalline metallic solids in Table 4, the covalent radii of 15 atoms in Table 5, and the van der Waal radii of 13 atoms in Table 6.

The following general observations transpire from a comparative study of the sizes of atoms.

(i) From Table 4 it is distinct that the Pauling's radii of the atoms forming the crystalline solids are systematically smaller in size than the radii of such atoms of the present calculation. This trend in size in the two methods is perfectly justified. The rationale may be as follows: In the crystalline solids, metal atoms do not remain as undistorted atoms rather the valence electrons of the metal atoms form a completely delocalized band and the lattice is a giant molecule. The metal ions and not the metal atoms 
Table 4. Comparative study of theoretical radii and Pauling's experimental metallic radii of atoms.

\begin{tabular}{|c|c|c|c|c|c|}
\hline Atoms & $\begin{array}{c}\text { Theoretical } \\
\text { atomic radii }(\AA \mathbf{A})\end{array}$ & $\begin{array}{l}\text { Single bond metallic } \\
\text { radii }(\AA)\end{array}$ & Atoms & $\begin{array}{c}\text { Theoretical } \\
\text { atomic radii }(\AA)\end{array}$ & $\begin{array}{l}\text { Single bond metallic } \\
\text { radii }(\AA)\end{array}$ \\
\hline $\mathrm{Li}$ & 1.6282 & 1.225 & Mo & 3.0677 & 1.296 \\
\hline $\mathrm{Be}$ & 1.0855 & 0.889 & $\mathrm{Tc}$ & 2.9398 & 1.271 \\
\hline $\mathrm{Na}$ & 2.1649 & 1.572 & $\mathrm{Ru}$ & 2.8222 & 1.246 \\
\hline $\mathrm{Mg}$ & 1.6711 & 1.364 & $\mathrm{Rh}$ & 2.7137 & 1.252 \\
\hline $\mathrm{Al}$ & 1.3607 & 1.248 & $\mathrm{Pd}$ & 2.6132 & 1.283 \\
\hline K & 3.5598 & 2.025 & $\mathrm{Ag}$ & 2.5199 & 1.339 \\
\hline $\mathrm{Ca}$ & 2.7479 & 1.736 & $\mathrm{Cd}$ & 2.433 & 1.413 \\
\hline $\mathrm{Sc}$ & 2.6106 & 1.439 & In & 2.1167 & 1.497 \\
\hline $\mathrm{Ti}$ & 2.4861 & 1.324 & $\mathrm{Sn}$ & 1.8732 & 1.399 \\
\hline $\mathrm{V}$ & 2.3732 & 1.224 & Cs & 6.0615 & 2.35 \\
\hline $\mathrm{Cr}$ & 2.2701 & 1.176 & $\mathrm{Ba}$ & 4.6788 & 1.981 \\
\hline Mn & 2.1754 & 1.171 & $\mathrm{La}$ & 3.8102 & 1.69 \\
\hline $\mathrm{Fe}$ & 2.0885 & 1.165 & Hf & 1.0079 & 1.442 \\
\hline Co & 2.008 & 1.162 & $\mathrm{Ta}$ & 0.9594 & 1.343 \\
\hline NI & 1.9337 & 1.154 & $\mathrm{~W}$ & 0.9165 & 1.304 \\
\hline $\mathrm{Cu}$ & 1.8648 & 1.173 & $\operatorname{Re}$ & 0.8773 & 1.283 \\
\hline $\mathrm{Zn}$ & 1.8004 & 1.249 & Os & 0.8413 & 1.26 \\
\hline $\mathrm{Ga}$ & 1.5663 & 1.245 & Ir & 0.8082 & 1.265 \\
\hline $\mathrm{Ge}$ & 1.3862 & 1.223 & $\mathrm{Pt}$ & 0.7776 & 1.295 \\
\hline $\mathrm{Rb}$ & 4.8106 & 2.16 & $\mathrm{Au}$ & 0.7492 & 1.336 \\
\hline $\mathrm{Sr}$ & 3.7135 & 1.914 & $\mathrm{Hg}$ & 3.0656 & 1.44 \\
\hline Y & 3.5278 & 1.616 & $\mathrm{Tl}$ & 2.667 & 1.549 \\
\hline $\mathrm{Zr}$ & 3.3598 & 1.454 & $\mathrm{~Pb}$ & 2.3603 & 1.539 \\
\hline $\mathrm{Nb}$ & 3.2071 & 1.342 & & & \\
\hline
\end{tabular}

Table 5. Comparative study of theoretical radii and Pauling's experimental covalent radii of atoms.

\begin{tabular}{cccccc}
\hline Atoms & $\begin{array}{c}\text { Theoretical } \\
\text { atomic radii }\left(\AA^{\mathbf{A}}\right)\end{array}$ & $\begin{array}{c}\text { Experimental } \\
\text { covalent radii }(\stackrel{(\AA)}{ })\end{array}$ & Atoms & $\begin{array}{c}\text { Theoretical } \\
\text { atomic radii }\left(\AA^{\circ}\right)\end{array}$ & $\begin{array}{c}\text { Experimental } \\
\text { covalent radii }(\AA)\end{array}$ \\
\hline $\mathrm{B}$ & 0.8141 & 0.88 & $\mathrm{Cl}$ & 0.7807 & 0.99 \\
$\mathrm{C}$ & 0.6531 & 0.77 & $\mathrm{As}$ & 1.2431 & 1.18 \\
$\mathrm{~N}$ & 0.5427 & 0.7 & $\mathrm{Se}$ & 1.1269 & 1.14 \\
$\mathrm{O}$ & 0.4652 & 0.66 & $\mathrm{Br}$ & 1.0305 & 1.11 \\
$\mathrm{~F}$ & 0.4071 & 0.64 & $\mathrm{Sb}$ & 1.6799 & 1.36 \\
$\mathrm{Si}$ & 1.1476 & 1.17 & $\mathrm{Te}$ & 1.5228 & 1.32 \\
$\mathrm{P}$ & 0.9922 & 1.1 & $\mathrm{I}$ & 1.3926 & 1.28 \\
$\mathrm{~S}$ & 0.8738 & 1.04 & & & \\
\hline
\end{tabular}


Table 6. Comparative study of absolute radii and covalent radii of Politzer-Parr-Murphy.

\begin{tabular}{ccc}
\hline Atoms & Covalent radii $(\mathbf{\AA})$ & Absolute radii $(\mathbf{\AA})$ \\
\hline $\mathrm{Li}$ & 1.357 & 1.6282 \\
$\mathrm{Na}$ & 1.463 & 2.1649 \\
$\mathrm{Al}$ & 1.487 & 1.3607 \\
$\mathrm{~K}$ & 1.802 & 3.5598 \\
$\mathrm{Cr}$ & 1.494 & 2.2701 \\
$\mathrm{Ni}$ & 1.3 & 1.9337 \\
$\mathrm{Cu}$ & 1.166 & 1.8648 \\
$\mathrm{Rb}$ & 1.924 & 4.8106 \\
$\mathrm{Ag}$ & 1.28 & 2.5199 \\
$\mathrm{Sn}$ & 1.492 & 1.8732 \\
$\mathrm{Te}$ & 1.381 & 1.5228 \\
$\mathrm{~B}$ & 1.091 & 0.8141 \\
$\mathrm{C}$ & 0.912 & 0.6513 \\
$\mathrm{~N}$ & 0.814 & 0.5427 \\
$\mathrm{O}$ & 0.764 & 0.4652 \\
$\mathrm{~F}$ & 0.671 & 0.4071 \\
$\mathrm{Si}$ & 1.296 & 1.1476 \\
$\mathrm{P}$ & 1.185 & 0.9922 \\
$\mathrm{~S}$ & 1.12 & 0.8738 \\
$\mathrm{Cl}$ & 0.999 & 0.7807 \\
$\mathrm{As}$ & 1.258 & 1.2431 \\
$\mathrm{Se}$ & 1.209 & 1.1269 \\
$\mathrm{Br}$ & 1.116 & 1.0305 \\
$\mathrm{Sb}$ & 1.433 & 1.6799 \\
$\mathrm{I}$ & 1.299 & 1.3926 \\
\hline
\end{tabular}

occupy the positions of atoms and held by strong cohesive force. Therefore, because of the strong cohesive force of metallic bonding in the lattice, the metal ions become very close and the inter nuclear distance between two immediate neighbours must be considerably smaller compared to a sum of the absolute radii of two atoms. Hence Pauling's determination of atomic radii by the apportionment of the distance of inter nuclear separation to the atoms in crystalline lattice does not refer to the absolute size of the atoms at all. Thus the smaller magnitude of Pauling's radii, compared to the absolute radii of present calculation is quite justified. We have one more precedent example [39] where theoretical absolute radii of atoms are greater than the so-called experimental radii. Waber and Larson [39] independently used the principal maximum of the charge densities as the orbital radii of the rare earth atoms and they used the nonrelativistic Hartree- Fock eigen functions to compute the orbital radii of free lanthanide atoms. They also concluded that the radii corresponding to these outer orbitals were significantly larger than the atomic or metallic radii. The Pauling's radii do not really represent the absolute radii of atoms rather such radii should be used to reproduce the distance of closest approach of two atoms in crystalline solid.

(ii) From Table 5 we see that, out of 15 elements, the covalent radii of as many as 6 elements are very close in both methods. The rest of the elements cited in Table 5 have radii both smaller and larger than the absolute radii of the present calculation. The covalent radii depend upon the force of covalent 
binding and the bond order. Since the type of covalent bonding is not uniform rather atoms may be bonded by single, double and triple bond depending upon the chemical situation, no general trend of correlation of theoretical absolute radii and covalent radii of atoms can be predicted.

(iii) A comparative study is also made between theoretical covalent radii of atoms of Politzer, Parr and Murphy [40] and the corresponding absolute radii of present calculation. Based on density functional theory, DFT, Politzer, Parr and Murphy [40] enquired into the relationship between atomic chemical potentials, electrostatic potentials and covalent radii and observed that the points at a certain radial distance at which electrostatic potential is equal to the chemical potential corresponds to the covalent radii. These covalent radii may be defined as theoretical covalent radii. Politzer et al [40] published the theoretical covalent radii of atoms of as many as 25 elements. We have arranged the theoretical radii and the corresponding absolute radii in the Table 6. A close look at the Table 6 reveals a strange behavior of the absolute radii vis-à-vis the theoretical covalent radii of atoms of corresponding elements. Absolute radii of the metallic atoms are consistently larger while the absolute radii of the non-metallic atoms are consistently smaller than the theoretical covalent radii of the atoms. However, the absolute radii of a few elements are also close to the theoretical covalent radii. This strange pattern of variation of the two sets of radii cannot be correlated unless the fundamental relationship between the covalent radii and the absolute radii is explored.

(iv) The van der Waal's radii.

It is sporadically sprinkled impression in the chemical literature that the inert gas atoms are unusually big in size. The published data very often shows that radii of the inert gas atoms is the biggest in the row where it occurs and that too, in violation of periodic law. Looking at the Table 7 we see that the van der Waal's radii in Pauling's determination are considerably larger than the absolute radii of the present calculation. In this connection we feel pertinent to make a more critical survey and study of the van der Waal radii of inert gas elements. The periodic law demands that the atomic size should be a monotone decreasing function of atomic number in a horizontal row and the size of the end element, the inert gas atom, must be smallest in the row. The formula of computing the theoretical radii shows that the absolute size of the atoms of the inert gas elements must be smallest in the row.

Table 7. Comparative study of theoretical radii and Pauling's experimental van der Waal's radii of atoms.

\begin{tabular}{cccccc} 
Atoms & $\begin{array}{c}\text { Theoretical } \\
\text { atomic radii }(\AA)\end{array}$ & $\begin{array}{c}\text { Experimental van } \\
\text { der Waal's radii }(\AA)\end{array}$ & Atoms & $\begin{array}{c}\text { Theoretical } \\
\text { atomic radii }(\AA)\end{array}$ & $\begin{array}{c}\text { Experimental van der } \\
\text { Waal's radii }(\AA)\end{array}$ \\
\hline $\mathrm{N}$ & 0.5427 & 1.5 & $\mathrm{Se}$ & 1.1269 & 2 \\
$\mathrm{P}$ & 0.9922 & 1.9 & $\mathrm{Te}$ & 1.5228 & 2.2 \\
$\mathrm{As}$ & 1.2431 & 2 & $\mathrm{~F}$ & 0.4071 & 1.35 \\
$\mathrm{Sb}$ & 1.6799 & 2.2 & $\mathrm{Cl}$ & 0.7807 & 1.8 \\
$\mathrm{H}$ & 0.5292 & 1.2 & $\mathrm{Br}$ & 1.0305 & 1.95 \\
$\mathrm{O}$ & 0.4652 & 1.4 & $\mathrm{I}$ & 1.3926 & 2.15 \\
$\mathrm{~S}$ & 0.8738 & 1.85 & & & \\
\hline
\end{tabular}


The available data regarding the size of the inert gas atoms in the chemical literature are all van der Waal radii. Since the van der Waal force of attraction is very weak, the gap between the atoms bonded by van der Waal bond is large and the van der Waal radii so computed must be very large. Thus, there is no reason of mysterious swelling of size of inert gas atoms as implied by their experimental radii. Justifiably, the absolute sizes of such atoms must be considerably smaller than their van der Waals radii. The radii of inert gas atoms in the present calculation are in conformity with the periodic law.

\section{Lanthanide Contraction.}

From the Table 1 and Figs. 1 and 2 we see that the present method of atomic radii calculation reproduces the "lanthanide contraction". To make the position more distinct and self-evident we have plotted the radii of atoms of 14 elements after lanthanum as a function of atomic number in Fig. 5. Fig. 5 demonstrates that the size of the lanthanide atoms decreases fairly regularly and steadily. Most of the textbooks speak about the sharp rise of the atomic radii of Eu and Yb. Instead of being contracted, atomic radii of these two elements are reported to be extremely large compared with other atoms of the series. The stated situation is self-evident in the curve reproduced in figure 14.4 at page 601 of the reference [5]. However, no rationale of abrupt increase in size of these two elements is put forward. The sharp increase in atomic size of $\mathrm{Eu}$ and $\mathrm{Yb}$ is missing in the curve of the calculated radii (Fig 5) and Table 1 shows that the orbital exponents of the outermost orbital of the atoms of the elements of lanthanide series steadily increase and as a consequence, the sizes of the atoms are bound to decrease steadily. Therefore, there is no scope of sudden increase in the size of Eu and Yb. However, we may try to rationalize the mystery of sudden increase in the reported crystal radii of $\mathrm{Eu}$ and $\mathrm{Yb}$. These two metal atoms form metallic bonds with two 's' electrons compared to the other lanthanides, which form metallic bonds with more than two electrons. Hence lanthanides other than Eu and $\mathrm{Yb}$ have more valance electrons for metallic binding and as a result such atoms become closer by stronger force of attraction reducing the inter nuclear distance and hence their smaller size. But $\mathrm{Eu}$ and $\mathrm{Yb}$ with fewer numbers of valence electrons form solids with relatively weaker force of attraction and hence the interatomic distance between two similar atoms in metallic state should be comparatively large. The fault lies in the method of determination of radii of atoms of such elements. So the apparent difference in the general appearance of atomic radii curve of lanthanides of the present calculation and that in reference [5] is rationalized. Thus the present theoretical determination of the sizes of the lanthanide elements is internally consistent and physically justified.

\section{Actinide Contraction.}

We know that according to the suggestion of Seaborg [41], known as actinide hypothesis, the elements following Ac form a new inner transition series analogous to the lanthanide elements. The Figs. 1 and 2 reveal that there is a steady decrease in sizes of the atoms of elements after actinium and the Table 1 shows that the orbital exponents of the outermost orbital of all such elements increase 
monotonically. To have a clearer view of the matter of actinide contraction in the present calculation, the radii of all 14 elements from Th to $\mathrm{Lr}$ are plotted as function of atomic number in Fig.6. The Fig.6 demonstrates distinctly the actinide contraction where the atoms of actinide elements undergo slow but steady decrease in size. Thus the physical reality of periodic size contraction among the lanthanide and actinide elements of the periodic table is realistically reproduced in the present set of theoretical atomic radii.

Waber and Cromer [8] calculated the theoretical radii of a number of atoms through the same formalism of radial charge density function but the orbitals are computed by the relativistic HartreeFock method. The trend of regular variation of atomic size in the d-block contraction, lanthanide contraction was reproduced in their work.

\section{Diamagnetic part of the atomic susceptibility.}

Partington [42] remarked that the Lother Meyer's atomic volume curve shows the periodicity of a number of physico-chemical properties including magnetic susceptibility. The diamagnetic part of magnetic susceptibility of as many as 54 elements is computed through the eqn. (9) and the computed values of $\left\langle\mathrm{r}^{2}\right\rangle_{\text {av }}$ and $\chi_{\text {dia }}$ are shown in Table 2 and plotted in Fig. 7 as a function of atomic number. A comparison of the Figs. 7 and 1 reveals that the nature of the curve for $\left\langle r^{2}\right\rangle_{\text {av }}$ is quite periodic in nature and mimics pattern of the atomic size curve and it further transpires that the diamagnetic part of magnetic susceptibility of the atoms, $\chi_{\text {dia, }}$ basically a size property, varies periodically like other periodic properties of elements. The study of the nature of the profiles of the two curves in Fig. 7 reveals that the curve of $\chi_{\text {dia }}$, and the curve of $\left\langle\mathrm{r}^{2}\right\rangle_{\text {av }}$ are homomorphic to each other. Now comparing the pattern of the profile of the diamagnetic susceptibility of atoms in Fig.7 with the pattern of the curve of the magnetic susceptibilities of atoms published in American Institute of Physics Handbook [43], it is apparent that the general appearance of the two curves have some resemblance. We further note that the position of occurrence of the inert gas elements in the curve of Figure 7 and the curve of the American Institute of Physics Handbook [43] are similar. It is also apparent from a comparative study of the values of the $\chi_{\text {dia }}$ of the present calculation (Table 2) and that published in CRC Handbook [44] that the trend of variation of the magnitude of the values of $\chi_{\text {dia }}$, of inert gas atoms as calculated by the present method and that published in the CRC Handbook [44] is similar in nature.

\section{The Periodicity of Atomic Polarizability $(\alpha)$ and Global Hardness $(\eta)$}

Chattaraj and Maity [45] have recently pointed out that the hardness and polarizability of atoms are periodic properties of the elements and the periodicity of these properties can be justified and formulated on the basis of maximum hardness principle, MHP [24,28,46] and the minimum polarizability principle, MPP [47]. It follows from MHP and MPP that an atom with a closed-shell structure is the most stable, hardest,and least polarizable among all the atoms in a given period and in general, the polarizabilty decreases along a period and increses along a group while the hardness has 
the reverse trend. The hardness increases along a period and decreases along a group. Thus, like other periodic physico-chemical properties, the global hardness and polarizability of elements are the periodic functions of the atomic number. The trend of variation of atomic polarizability in groups and periods set in this work was also predicted earlier [19].

\section{Atomic polarizability ( $\alpha)$.}

From the eqn.14 we find that the atomic polarizability, $\alpha$ is directly proportional to the size of the atoms. Comparing the experimental [19] atomic polarizability of as many as nine elements with the corresponding theoretical polarizability in Table 8 we see that the theoretical values are close to the experimental results of as many as eight elements. The Fig. 8 reveals that the polarizability profile mimics the atomic size curve of Fig.1. Thus the computed atomic polarizability is a perfect periodic physical property having the nature of variation similar to the atomic volume curve of Lother Meyer. A close look at Fig. 8 shows the set trend of variation of the atomic polarizability, $\alpha$. The polarizability increases steadily with increasing atomic number in a group, and it gradually decreases and ends at the atom of inert gas element in a period. But the trend of polarizability of the inert gases within the family must be increasing with increasing atomic number [45]. It is distinct from the Fig.8 that the alkali metal atoms appear at the top and the inert gas atoms occur at the bottom of the polarizability curve. Apparently, the alkali metal atoms, as a class, can be easily deformed by an electric field. The easy polarizability of the alkali metal atoms is due to the loosely bound outer or valance electrons in its structure. But the electronic structures of the noble gas atoms are much stiffer or hard. The expected pattern of variation of polarizability of the inert gas atoms within the group is also reproduced in the polarizabilities of atoms calculated in terms of theoretical atomic radii. From the above it transpires that the polarizabilities atoms computed in terms of the theoretical radii is quantitatively close to the experimental values and qualitatively reproduce the expected periodicity. Therefore, we can say that the theoretical atomic radii of the present calculation can be used to effectively compute the periodic physical property of atoms of the elements - the atomic polarizability.

Table 8. Comparative study of theoretical and experimental atomic polarizability of some elements.

\begin{tabular}{ccc}
\hline Atoms & $\begin{array}{c}\text { Theoretical Atomic } \\
\text { Polarizability }\left(\mathbf{x ~ 1 0} \mathbf{~}^{-24} \mathbf{c c}\right)\end{array}$ & $\begin{array}{c}\text { Experimental Atomic } \\
\text { Polarizability }\left(\mathbf{x ~ 1 0} \mathbf{~}^{-24} \mathbf{c c} .\right)\end{array}$ \\
\hline $\mathrm{H}$ & 0.6669 & 0.66 \\
$\mathrm{He}$ & 0.1358 & 0.21 \\
$\mathrm{Li}$ & 19.4239 & 12 \\
$\mathrm{Be}$ & 5.7558 & 9.3 \\
$\mathrm{C}$ & 2.4279 & 1.5 \\
$\mathrm{Ne}$ & 1.2432 & 0.4 \\
$\mathrm{Na}$ & 45.659 & 27 \\
$\mathrm{Ar}$ & 1.5808 & 1.6 \\
$\mathrm{~K}$ & 202.9969 & 34 \\
\hline
\end{tabular}




\section{Global Hardness $(\eta)$.}

The hardness is an intrinsic periodic physical property of atoms [45]. The global hardness of 103 elements is computed through eqn.(19) using the values of theoretical atomic radii and shown in Table 3. Pearson [31] correlated the global hardness, $\eta$, with the polarizability of the atoms. Although the global hardness has been rigorously defined by Density Functional Theory, the qualitative idea is still a valuable guide. We see from eqn.19 that, since e, the electronic charge is constant, the global hardness of the atoms, $\eta$ is inversely proportional to $R$, the radius of the atoms. Thus the hardness is determined by the size factor of atoms only. We have plotted the computed global hardness of atoms as a function of atomic number in Figure 9. The general appearance of the profile of global hardness of atoms as revealed in Fig. 9 is periodic in nature and has resemblance to the atomic volume curve of Lother Meyer in Fig. 1. The alkali metals have the smallest hardness and the inert gas atoms have the largest hardness and the hardness increases monotonically horizontally in a period. The hardness decreases vertically in a group. The same pattern is repeated in all the periods and groups. Thus, it is transparent that the hardness values of atoms computed in terms of the atomic radii of the present work meaningfully exhibit its qualitative periodic nature. Now we seek a quantitative correlation of the computed hardness of the atoms. A number of informations have appeared regarding the numerical values of global hardness of atoms $[6,22,27,31,48]$ of which the hardness values of Parr and Pearson [27], and Pearson [31] were calculated from the experimental ionization potential and electron affinity. It appears that the values of hardness of atoms calculated by Pearson [31] are absolute. In the Table 9 we have tabulated, side by side, the hardness values of atoms of 63 elements calculated by Pearson [31] and the hardness values of the corresponding atoms calculated through eqn.19. A close look at the values of the hardness calculated by Pearson [31] on the basis of experimental ionization potential and electron affinity reveals that in a significant number of cases the expected relative order of the hardness and radii are inverted and the atoms of smaller radii has smaller hardness and the atoms of larger radii has larger hardness in violation of periodic law. However, comparing the values of hardness of present calculation vis-à-vis and those published by Pearson [31], we find that the theoretically computed values of global hardness of as many as 26 of atoms are close (within 0.1 to1.0 $\mathrm{eV}$ ) to that of Pearson's values. Thus we conclude that the result is encouraging both qualitatively and quantitatively.

\section{Conclusion.}

The terms atomic and ionic radii are very popular in chemical literature and the concept has been largely employed in rationalizing various physico-chemical properties of atoms and molecules and is a useful parameter of electronic structure theory. We have explored a simple method of computing the absolute size of atoms and brought together a large body of known material to reveal how many different properties correlate with atomic size. Although a large body of scattered information on sizes of atoms and ions has appeared in the literature, a critical analysis of the status of a reported set of radii 
Table 9. Comparative study of theoretical and absolute global hardness (atoms having theoretical hardness close within $0.1-1.0 \mathrm{eV}$ to the experimental are given asterisks).

\begin{tabular}{|c|c|c|c|c|c|}
\hline Atoms & $\begin{array}{c}\text { Theoretical Global } \\
\text { hardness of atoms } \\
(\mathrm{eV})\end{array}$ & $\begin{array}{c}\text { Absolute Global } \\
\text { hardness of atoms } \\
(\mathrm{eV})\end{array}$ & Atoms & $\begin{array}{c}\text { Theoretical Global } \\
\text { hardness of atoms } \\
(\mathrm{eV})\end{array}$ & $\begin{array}{c}\text { Absolute Global } \\
\text { hardness of atoms } \\
(\mathrm{eV})\end{array}$ \\
\hline $\mathrm{H}$ & 13.588 & 6.43 & $\mathrm{Rb}^{*}$ & 1.4948 & 1.85 \\
\hline $\mathrm{Li}$ & 4.4164 & 2.39 & $\mathrm{Sr}$ & 1.9364 & 3.7 \\
\hline $\mathrm{Be}$ & 6.6244 & 4.5 & $\mathrm{Yb}$ & 2.0383 & 3.19 \\
\hline $\mathrm{B}$ & 8.8328 & 4.01 & $\mathrm{Zr}$ & 2.1402 & 3.21 \\
\hline $\mathrm{C}$ & 11.0407 & 5 & $\mathrm{Nb}^{*}$ & 2.2422 & 3 \\
\hline $\mathrm{N}$ & 13.25 & 7.23 & Mo* & 2.344 & 3.1 \\
\hline $\mathrm{O}$ & 15.4574 & 6.08 & $\mathrm{Ru}^{*}$ & 2.5479 & 3 \\
\hline $\mathrm{F}$ & 17.6634 & 7.01 & $\mathrm{Rh}^{*}$ & 2.6498 & 3.16 \\
\hline $\mathrm{Na}^{*}$ & 3.3215 & 2.3 & $\mathrm{Pd}$ & 2.7517 & 3.89 \\
\hline $\mathrm{Mg}^{*}$ & 4.303 & 3.9 & $\mathrm{Ag} *$ & 2.8536 & 3.14 \\
\hline $\mathrm{Al}$ & 5.2846 & 2.77 & $\mathrm{Cd}$ & 2.9555 & 4.66 \\
\hline $\mathrm{Si}$ & 6.2659 & 3.38 & $\operatorname{In} *$ & 3.3972 & 2.8 \\
\hline $\mathrm{P}$ & 7.2473 & 4.88 & $\mathrm{Sn} *$ & 3.8388 & 3.05 \\
\hline $\mathrm{S}$ & 8.2293 & 4.14 & $\mathrm{Sb}^{*}$ & 4.2805 & 3.8 \\
\hline $\mathrm{Cl}$ & 9.2107 & 4.68 & $\mathrm{Te}$ & 4.7221 & 3.52 \\
\hline $\mathrm{K}^{*}$ & 2.02 & 1.92 & I & 5.1636 & 3.69 \\
\hline $\mathrm{Ca}$ & 2.6168 & 4 & Cs* & 1.1863 & 1.71 \\
\hline $\mathrm{Sc}^{*}$ & 2.7545 & 3.2 & $\mathrm{Ba}$ & 1.5369 & 2.9 \\
\hline Ti* & 2.8924 & 3.37 & $\mathrm{La}^{*}$ & 1.8873 & 2.6 \\
\hline $\mathrm{V}^{*}$ & 3.03 & 3.1 & Hf & 7.1344 & 3 \\
\hline $\mathrm{Cr}^{*}$ & 3.0676 & 3.06 & $\mathrm{Ta}$ & 7.4951 & 3.79 \\
\hline $\mathrm{Mn}^{*}$ & 3.3055 & 3.72 & $\mathrm{~W}$ & 7.8459 & 3.58 \\
\hline $\mathrm{Fe}^{*}$ & 3.443 & 3.81 & $\mathrm{Re}$ & 8.1965 & 3.87 \\
\hline $\mathrm{Co}^{*}$ & 3.5811 & 3.6 & Os & 8.5472 & 3.8 \\
\hline $\mathrm{Ni}^{*}$ & 3.7187 & 3.25 & $\mathrm{Ir}$ & 8.8973 & 3.8 \\
\hline $\mathrm{Cu}$ & 3.8561 & 3.25 & $\mathrm{Pt}$ & 9.2474 & 3.5 \\
\hline $\mathrm{Zn} *$ & 3.994 & 4.94 & $\mathrm{Au}$ & 9.598 & 3.46 \\
\hline $\mathrm{Ga}$ & 4.5909 & 2.9 & $\mathrm{Hg}$ & 2.3456 & 5.54 \\
\hline $\mathrm{Ge}$ & 5.1874 & 3.4 & $\mathrm{Tl} *$ & 2.6962 & 2.9 \\
\hline As & 5.7846 & 4.5 & $\mathrm{~Pb}^{*}$ & 3.0466 & 3.53 \\
\hline $\mathrm{Se}$ & 6.381 & 3.87 & $\mathrm{Bi}^{*}$ & 3.3972 & 3.74 \\
\hline $\mathrm{Br}$ & 6.978 & 4.22 & & & \\
\hline
\end{tabular}

and inter-relationship between various sets of radii seems to have not been taken up. The scientific workers often feel the need of more representative atomic and ionic radii than that available in chemical literature. Powell [49] has stated that the structure, stability and reactivity of organolanthanide compounds seem to be largely determined by electrostatic and steric effects and by selecting a metal of appropriate size it may in future be possible to tailor the steric effect so as to provide just right environment to bring about a desired reaction. The present theoretical investigation of physical problem of atomic size has been found largely successful in providing with an unambiguous concept of the absolute size of atoms and rationalizing the range of validity and status of various sets of reported atomic radii by a qualitative and quantitative study. The computed theoretical radii qualitatively reproduce the periodic table and the atomic volume curve of Lother Meyer. A comparative study of the relative sizes of the atoms in groups and periods reveals that the expected 
vertical trend of variation in a group and the horizontal trend in a period in atomic size are nicely reproduced by the theoretical atomic radii. The d-block and f-block contractions are also distinct in the calculated sizes. The atomic radii of present calculation are found to have a good correlation with other available so called experimental radii and theoretical radii computed through more sophisticated method. The computed size is applied to calculate the periodic size dependent physical properties of distinct and isolated atoms: the diamagnetic part of the atomic susceptibility, the atomic polarizability and the global hardness. The computed theoretical results have a good resemblance with experimental data. In a significant number of cases the theoretically computed physical properties in terms of the absolute radii calculated by the present method are quantitatively close to their experimental values. The atomic radii of present calculation are found to have a good correlation with other available theoretical radii computed through more sophisticated method. Thus, the present approach of computing the absolute size of atoms in a simple way seems to be a successful venture and should be exploited as fully as possible.

\section{Acknowledgement.}

One of the authors, R. B, is grateful to the University of Kalyani for financial assistance.

\section{References.}

1. a) Goldschmidt, V.M Skrifter Norske Videnskaps-Akad. Osls 1926, 2.

b) Goldschmidt, V.M Skrifter Norske Videnskaps-Akad. Osls 1927, 8.

c) Goldschmidt, V.M Trans.Faraday Soc. 1929, 25, 253.

d) Goldschmidt, V.M Geochemische Verteilungsgesetze der Elemente 1926, 8, 69.

e) Goldschmidt, V.M Ber. 1927, 60, 1263.

2. Pauling, L. The nature of the chemical bond and the structure of molecules and crystals: An introduction to modern structural chemistry; Third Edition; Cornell University Press: Ithaka, NY; 1960.

3. a) Zachariasen, W.H. Z. Krist 1931, 80, 137.

b) Zachariasen, W.H. Phys. Rev 1948, 73, 1104.

4. Bragg, W.L Phil. Mag. 1920, 40, 169.

5. Huheey, J.E.; Keiter, E.A.; Keiter, R.L. Inorganic Chemistry, Priciples of Structure and Reactivity; Fourth Edition, Addition-Wesley Publishing Company, 1993.

6. Nagle, J.K. J. Am. Chem. Soc. 1990, 112, 4741.

7. a)Slater, J.C. J. Chem. Phys. 1964, 41, 3199.

b) Slater, J.C. Quantum Theory of Moleculs and Solids; McGraw-Hill Book: New York; Vol. 2.

8. Waber, J.T.; Cromer, D.T. J. Chem. Phys. 1965, 42, 4116.

9. Bohr, N. Phil. Mag. 1922, 9.

10. Slater J. C.; Phys Rev. 1930, 36, 57. 
11. Clementi, E.; Raimondi, D. L. J. Chem. Phys. 1963, 38, 2686.

12. Hertzberg, G. Atomic Spectra and Atomic Structure; Dover Publication: New York, 1944.

13. Atskin, P. W.; Friedman, R. S. Molecular Quantum Mechanics; $3^{\text {rd }}$ Edition, Oxford University Press: Oxford, 1997.

14. Pople, J.A.; Beveridge, D.L. Approximate Molecular Orbital Theory; McGraw-Hill Book Company, 1970.

15. Shriver, D. F.; Atkins, P. W.; Langford, C. H. Inorganic Chemistry; $3^{\text {rd }}$ ed.; Oxford University Press: Oxford, 1999.

16. Glasstone, S. Text Book of Physical Chemistry, Mcmillan Student Editions, Mcmillan and Co.: London.

17. Selwood, P. W.; Magnetochemistry, Second Edition, Interscience Publishers: New York, 1956.

18. Feynman, R. P.; Leighton, R. B.; and Sands, M. The Feynman Lecture on Physics, AddisonWesley: Mass., Vol. II., 1964.

19. Purcell, E. M. Berkley Physics Course, TMH Edition, Tata McGraw-Hill Publishing Company: Bombay- New Delhi, Vol. 2, 1963.

20. a) Pearson, R. G. J. Am. Chem. Soc. 1963, 85, 3533.

b) Pearson, R. G. Science 1966, 172, 151.

21. Brinck, T.; Murray, J. S.; Politzer, P. J. Chem. Phys. 1993, 98, 4305.

22. Hati, S.; Dutta. D. J. Phys. Chem. 1994, 98, 10451.

23. Dmitrieva, I. K.; Plindov, G. I. Phys. Scr. 1983, 27, 734.

24. Pearson, R. G. J. Chem. Educ. 1999, 76, 267.

25. Mulliken, R. S. J. Am. Chem. Soc. 1952, 74, 811.

26. Parr, R. G.; Donnelly, R. A.; Levy, M.; Palka, W. E. J. Chem. Phys. 1978, 69, 4431.

27. Parr, R. G.; Pearson, R. G. J. Am. Chem. Soc. 1983, 105, 7512.

28. Pearson, R. G. J. Chem. Educ. 1987, 64, 561.

29. Parr, R. G.; Chattaraj, P. K. J. Am. Chem. Soc. 1991, 113, 1854.

30. Parr R. G.; Yang. W. Density Functional Theory of Atoms and Molecules, Oxford University Press: New York, N.Y., 1989.

31. Pearson, R. G. Inorg. Chem. 1988, 27, 734.

32. Goh, N. K.; Chia, L. S. J. Chem. Educ. 1989, 66, 747.

33. Masteulon W. L.; Slowinski E. J. Chemical Principles, $4^{\text {th }}$ Edition, Saunders: London, 1977.

34. Mason, J. J. Chem. Educ. 1988, 65, 17.

35. Arhens, L. H. Geochem. Cosmochem. Acta. 1952, 2, 155.

36. Sproul, G. J. Chem. Educ. 2001, 78, 387.

37. Murphy,L. R.; Meek, L.; Alred, A. L.; Allen, L. C. J. Phys. Chem. A 2000, 104, 5867.

38. Chattaraj, P. K.; Sengupta, S. J. Phys. Chem. 1996, 100, 16126.

39. Waber, J. T.; Larson, A. C. Rare Earth Res. Conf. Clear Water, Fla. 1963, 3, 361. 
40. Politzer, P.; Parr, R. G.; Murphy, D. R. J. Chem. Phys. 1983, 79, 3859.

41. Seaborg, G. T. The transuranium elements, (Research Papers), Part-II, Papers: 6.40 to 22.80, 1492.

42. Partington, J. R. General and Inorganic Chemistry, Mcmillan: London, 1967.

43. American Institute of Physics Handbook, 2nd Edition, McGraw Hill, 5-218, fig- 5g-11.

44. CRC Hand Book of Chemistry and Physics.; Lide, D.R., Ed.; 74th Edition, CRC Press; 1993-1994.

45. Chattaraj, P. K.; Maiti, B. J. Chem. Educ. 2001, 78, 811.

46. a) Pearson, R. G. Acc. Chem. Res. 1993, 26, 250.

b) Parr, R. G.; Chattaraj, P. K. J. Am. Chem. Soc. 1991, 113, 1854.

c) Chattaraj, P. K.; Liu, G. H.; Parr, R.G. Chem. Phys. Lett. 1995, 237, 171.

d) Ayers, P. W.; Parr, R.G. J. Am. Chem. Soc. 2000, 122, 2010.

47. a) Chattaraj, P. K.; Sengupta, S. J. Phys. Chem. 1996, 100, 16126.

b) Chattaraj, P. K.; Sengupta, S. J. Phys. Chem. 1997, A 42, 7893.

c) Chattaraj, P. K.; Poddar, A. J. J. Phys. Chem. 1998, A 102, 9944.

48. Ghanty, T. K.; Ghosh, S. K. J. Phys. Chem., 1996, 100, 17429.

49. Powell., P. Principle of Organometallic Chemistry, Second Edition, Chapman and Hall: London, New York, Tokyo, Melbourne, Madras; 1988.

(c) 2002 by MDPI (http://www.mdpi.org), Basel, Switzerland. 